\title{
Experimental zircon/melt and zircon/garnet trace element partitioning and implications for the geochronology of crustal rocks
}

\author{
Daniela Rubatto*, Jörg Hermann \\ Research School of Earth Sciences, The Australian National University, Canberra 0200 ACT, Australia
}

Received 2 May 2006; received in revised form 1 November 2006; accepted 17 January 2007

\begin{abstract}
Garnet is the most commonly used mineral in thermobarometry, whereas zircon is the most robust chronometer to date high-grade metamorphic rocks. To provide a basis for correlation of zircon and garnet growth, we determined experimentally the trace element partitioning between zircon, a hydrous granitic melt and garnet at $20 \mathrm{kbar}$ and $800-1000^{\circ} \mathrm{C}$ for $\mathrm{P}, \mathrm{Y}$, rare earth elements (REE), $\mathrm{Zr}$, $\mathrm{Hf}, \mathrm{Th}$ and U. In respect to melt, zircon preferentially incorporates all investigated elements apart from REE with atomic number lower than Sm. At this pressure and in the chosen composition, the distribution coefficient between zircon and melt $\left(D^{\mathrm{Zm} / \mathrm{Melt}}\right)$ for REE increases with increasing atomic number of the REE and with decreasing temperature. $D_{\mathrm{Yb}}^{\mathrm{Znn} / \mathrm{Melt}}$ is $\sim 20$ at $1000^{\circ} \mathrm{C}$, but more than an order of magnitude higher at $800^{\circ} \mathrm{C}$. The solubility of $\mathrm{Zr}$ in hydrous granitic melts buffered by zircon is about a factor of two lower at $20 \mathrm{kbar}$ than what has been previously established for mid-crustal pressures. Large garnet produced in the experiments allowed determination of garnet $/$ melt trace element partitioning $\left(D^{\mathrm{Grt} / \mathrm{Melt}}\right)$ at temperatures of $800-1000{ }^{\circ} \mathrm{C}$, conditions relevant for partial melting of crustal rocks. There is a systematic increase in $D_{\mathrm{REE}}^{\mathrm{Grt} M e l t}$ with decreasing temperature. Zircon contains significantly more heavy-REE than garnet at temperatures of $800-850^{\circ} \mathrm{C}$. Zircon/garnet partition coefficients of heavy-REE decrease with increasing temperature from $D_{\mathrm{Lu}}^{\mathrm{Zn} / \mathrm{Melt}}$ of 12 at $800^{\circ} \mathrm{C}$ to 1.4 at $1000^{\circ} \mathrm{C}$. Middle-REE partitioning is close to unity for the whole investigated temperature range. Different empirically determined zircon/garnet partition coefficients from granulites and ultra-high temperature granulites can potentially be explained by the experimentally determined change of partitioning as a function of temperature. These data can assist in establishing equilibrium between garnet and zircon zones in natural rocks, and in the construction of detailed pressure-temperature-time paths in high-grade metamorphic rocks.
\end{abstract}

(C) 2007 Elsevier B.V. All rights reserved.

Keywords: Zircon; Garnet; Trace element partitioning; Experimental petrology; U-Pb geochronology

\section{Introduction}

Garnet and zircon are key minerals for the understanding of high-grade metamorphic processes and their chronology. Garnet is an indicator mineral of hightemperature and/or high-pressure metamorphism and is

\footnotetext{
* Corresponding author. Tel.: +6126125 5157; fax: +6126125 8345.

E-mail address: daniela.rubatto@anu.edu.au (D. Rubatto).
}

the main mineral used in thermobarometry. It is a common restitic phase during partial melting of crustal rocks and is an important sink for trace elements such as $\mathrm{Y}$ and the heavy rare earth elements (HREE) (e.g. Hickmott et al., 1987; Bea et al., 1994; Hermann, 2002; Otamendi et al., 2002; Rubatto and Hermann, 2003). HREE depletion of partial crustal melts is commonly used as evidence of restitic garnet in the source region (Otamendi and Patiño Douce, 2001). In contrast, zircon is one of the main accessory phases in crustal rocks. 
Because zircon contains significant amounts of $\mathrm{Y}, \mathrm{Zr}$, Hf, P, U, Th and middle-REE to heavy-REEs (e.g. Hinton and Upton, 1991), it is relevant for $\mathrm{U}-\mathrm{Pb}$ geochronology and for trace element budgets during high-grade metamorphism and anatexis (Watson and Harrison, 1983; Bea et al., 1994; Hoskin et al., 2000; Linnen and Keppler, 2002; Hoskin and Schaltegger, 2003; Rubatto and Hermann, 2003).

In order to fully exploit the wealth of information from high-grade metamorphic rocks, it is therefore critical to correlate the growth of zircon with garnet growth. This would allow the age of accessory zircon to be related to metamorphic conditions and hence to construct robust temperature-pressure-time path for high-grade metamorphic rocks. Additionally, such a correlation would allow the monitoring of crustal anatexis using a major and an accessory phase. It is very difficult to relate zircon to garnet growth on the basis of textural relationships because of the extreme difference in size. However, there is mounting evidence that this correlation is possible on the basis of trace element compositions. Garnet and zircon both show strong HREE enrichment with respect to chondrite values and display highly variable REE patterns. On the basis of the trace element composition of garnet and zircon found in partially molten rocks, a number of studies have determined empirical partitioning (Rubatto, 2002; Hermann and Rubatto, 2003; Whitehouse and Platt, 2003; Hokada and Harley, 2004; Kelly and Harley, 2005; Buick et al., 2006; Rubatto et al., 2006). The results obtained from different studies are in apparent disagreement, particularly for the HREE. A first group of studies (Rubatto, 2002; Hermann and Rubatto, 2003; Rubatto and Hermann, 2003; Buick et al., 2006; Rubatto et al., 2006) focused on granulite-facies rocks that underwent partial melting and new zircon growth at temperatures around $800{ }^{\circ} \mathrm{C}$ and variable pressures (4-9 kbar). These studies agree in calculating zircon garnet partitioning for the HREE above unity, between $0.7-2.3$ for Gd and increasing gradually to $6.3-24$ for Lu. A similar trend with partitioning increasingly in favour of zircon across the HREE has been documented in eclogite-facies rocks that never reached melting ( $T \sim 600{ }^{\circ} \mathrm{C}$ and $P \sim 20 \mathrm{kbar}$ ) and where metamorphic zircon likely formed by the interaction with fluids (Rubatto, 2002; Rubatto and Hermann, 2003). A second group of studies (Hokada and Harley, 2004; Kelly and Harley, 2005) dealt with zircon and garnet in Antarctic rocks that underwent ultra-high temperatures (UHT) up to $1100{ }^{\circ} \mathrm{C}$ at $\sim 7 \mathrm{kbar}$. These studies concluded that the zircon/garnet partitioning is equally close to unity across the HREE, between 1.3 and 0.6 for elements from Gd to
Lu. The work of Whitehouse and Platt (2003) investigated granulite facies rocks $\left(750-800{ }^{\circ} \mathrm{C}\right.$ and 8.5-9 kbar), and obtained zircon/garnet partitioning for the HREE close to unity.

In order to address the apparent disagreement of empirical data and to provide a basis for further correlation between zircon and garnet, we performed a series of piston-cylinder experiments at temperature conditions relevant for natural samples (temperature, $T$, between 800 and $1000{ }^{\circ} \mathrm{C}$ and pressure, $P$, of $20 \mathrm{kbar}$ ). The distribution of trace elements (P, Y, Zr, REE, Hf, Th and $\mathrm{U}$ ) between garnet, zircon and a hydrous granitic melt were determined for a synthetic NKCFMASH system. A comprehensive set of garnet $/ \mathrm{melt}$, zircon $/ \mathrm{melt}$ and zircon/garnet distribution coefficients was determined experimentally for the first time. The results permit an evaluation of the empirical data and explain some of the variations observed in nature.

\section{Experimental and analytical techniques}

\subsection{Starting material}

Different mechanisms have been proposed for the incorporation of REE in zircon, mainly involving $\mathrm{P}$ and H (e.g. Speer, 1982; Hinton et al., 2003; Hoskin and Schaltegger, 2003 and references therein; Spandler et al., 2004). Considering these constraints, we aimed at a starting material that contains water and moderate amounts of phosphorous. We avoided saturation of a phosphate phase because such a trace element-rich accessory phase would have interfered in the measurements of trace elements in the phases of interest. Because the melt composition is likely to play a role in partitioning, we have chosen a starting material with a granitic composition, so that the obtained results are relevant for crustal anatexis and granite formation. We have chosen a relatively high water content in the melt in order to suppress crystallization of phases other than garnet and zircon at the relatively low temperatures of the experiments.

In order to obtain a starting material homogeneous in $\mathrm{Zr}$ and trace elements, we produced first a zirconiumand phosphorus-free gel with the major elements $\mathrm{Si}, \mathrm{K}$, $\mathrm{Na}$ and all the other trace elements. About $2 \mathrm{wt} . \% \mathrm{ZrO}_{2}$ and $0.5 \mathrm{wt} . \%$ apatite was added and the mix was ground and melted to a glass at $1400{ }^{\circ} \mathrm{C}$. Inspection by optical microscopy, secondary-electron microscope (SEM) imaging and Laser Ablation-Inductively Coupled Plasma-Mass Spectrometry (LA-ICP-MS) revealed that the glass was homogenous. Aluminium was then added to the ground glass as $\mathrm{Al}(\mathrm{OH})_{3}$, in order to have an 
accurate amount of water in each experiment. The starting material was prepared by mixing $75-80 \%$ of a granite mix doped with trace elements with $20-25 \%$ of a hydrous garnet composition (Table 1) of $\mathrm{Alm}_{50} \mathrm{Py}_{40}$ $\mathrm{Grs}_{10}$ that was prepared by mixing fayalite, $\mathrm{SiO}_{2}, \mathrm{CaO}$, $\mathrm{Mg}(\mathrm{OH})_{2}$ and $\mathrm{Al}(\mathrm{OH})_{3}$. We tested a series of other compositions to produce large zircon grains by adding different amounts of alkalis and aluminium but the results obtained were not satisfactory. Only in a very alkali-rich, Al-poor composition were we able to grow zircons of 10-20 $\mu \mathrm{m}$ size, but garnet was not stable and therefore this composition was not further investigated. Some experiments were performed at high phosphorous content to monitor the effect of phosphorous saturation.

\subsection{Experimental set-up}

Synthesis experiments were run in an end-loaded $1.27 \mathrm{~cm}$ piston-cylinder apparatus. $15-20 \mathrm{mg}$ of sample

Table 1

Composition of starting material

\begin{tabular}{|c|c|c|c|}
\hline & Granite mix wt.\% & Garnet mix wt.\% & Typical run wt.\% \\
\hline $\mathrm{SiO}_{2}$ & 60.0 & 33.4 & 54.7 \\
\hline $\mathrm{Al}_{2} \mathrm{O}_{3}$ & 20.1 & 18.9 & 19.9 \\
\hline $\mathrm{FeO}$ & 0.0 & 20.6 & 4.1 \\
\hline $\mathrm{MgO}$ & 0.0 & 9.4 & 1.9 \\
\hline $\mathrm{CaO}$ & 2.4 & 3.4 & 2.6 \\
\hline $\mathrm{Na}_{2} \mathrm{O}$ & 2.6 & 0.0 & 2.1 \\
\hline $\mathrm{K}_{2} \mathrm{O}$ & 3.2 & 0.0 & 2.6 \\
\hline $\mathrm{TE}^{\mathrm{a}}$ & 2.2 & & \\
\hline $\mathrm{H}_{2} \mathrm{O}$ & 9.5 & 14.3 & 10.5 \\
\hline Total & 100.0 & 100.0 & 100.0 \\
\hline
\end{tabular}

\begin{tabular}{lrrrr} 
& Granite mix & & Typical run \\
\cline { 2 - 3 } $\mathrm{ppm}$ & Standard deviation $(n=7)$ & ppm \\
\hline $\mathrm{P}$ & 632 & 22 & 506 \\
$\mathrm{Y}$ & 453 & 7 & 362 \\
$\mathrm{Zr}$ & 9419 & 610 & 7538 \\
$\mathrm{Ba}$ & 405 & 4 & 324 \\
$\mathrm{La}$ & 477 & 8 & 382 \\
$\mathrm{Ce}$ & 407 & 8 & 326 \\
$\mathrm{Pr}$ & 379 & 7 & 303 \\
$\mathrm{Nd}$ & 448 & 9 & 359 \\
$\mathrm{Sm}$ & 410 & 9 & 328 \\
$\mathrm{Eu}$ & 380 & 8 & 304 \\
$\mathrm{Gd}$ & 392 & 8 & 314 \\
$\mathrm{Dy}$ & 410 & 8 & 328 \\
$\mathrm{Er}$ & 408 & 9 & 327 \\
$\mathrm{Yb}$ & 430 & 9 & 344 \\
$\mathrm{Lu}$ & 427 & 9 & 341 \\
$\mathrm{Hf}$ & 628 & 39 & 502 \\
$\mathrm{Th}$ & 453 & 16 & 362 \\
$\mathrm{U}$ & 511 & 17 & 409 \\
\hline
\end{tabular}

\footnotetext{
${ }^{\text {a }}$ Sum of trace elements as oxides.
}

was loaded in a gold capsule (outside diameter $2.3 \mathrm{~mm}$ ) and sealed by arc welding. The capsule was wrapped in wet tissue to keep the sample at $T$ below $100{ }^{\circ} \mathrm{C}$. Capsules were emplaced in the hot spot of a low friction assembly consisting of Teflon foil, salt sleeve, Pyrex glass, graphite heater and $\mathrm{MgO}$. Frequently, two different compositions were run at the same time (Fig. 1a). Pressure was adjusted several times during the first $24 \mathrm{~h}$ of runs to compensate pressure drop due to the release of initial internal friction and was later adjusted if needed. Generally, the experiment was held at $P$ and $T$ for about a week (Table 2) to optimise equilibration and to minimise potential $\mathrm{H}$ loss. Because run duration was much longer than $24 \mathrm{~h}$, there is no need for friction correction with this assembly. Thus, pressure in the experiments is measured by load on the piston and is accurate to $\pm 0.1 \mathrm{GPa}$. Temperature was controlled using type $\mathrm{B}$ thermocouples $\left(\mathrm{Pt}_{6} \mathrm{Rh}_{94} / \mathrm{Pt}_{30} \mathrm{Rh}_{70}\right)$ and is accurate to $\pm 10{ }^{\circ} \mathrm{C}$. The sample was quenched at the end of the run by terminating the power to the furnace. Oxygen fugacity was not buffered in the runs but the applied assembly produces conditions close to the Ni-NiO transition (W.O. Hibberson personal comm.). The stoichiometry of analysed garnets indicates that in all experiments less than $5 \%$ of the total iron is $\mathrm{Fe}^{3+}$ in the garnet. $\mathrm{No} \mathrm{Fe}^{3+}$ is expected in the melt. Hence, the great majority $(>96 \%)$ of the added iron remained as $\mathrm{Fe}^{2+}$. This indicates that there was neither significant alloying of Fe-metal nor diffusion of $\mathrm{H}$ through the gold capsule, which both produce $\mathrm{Fe}^{3+}$. The applied analytical technique with rastering the beam and applying low beam currents $(1 \mathrm{nA})$ allows estimation of the water content in the glasses on the basis of the obtained totals. The water content of the melt (see Section 4.1.) indicates that there has not been a measurable loss of $\mathrm{H}$. With almost all iron as $\mathrm{Fe}^{2+}$, we anticipate that $\mathrm{U}$ will be present as $\mathrm{U}^{4+}$ and $\mathrm{Ce}$ as $\mathrm{Ce}^{3+}$. This is supported by the absence of any detectable positive $\mathrm{Ce}$ anomaly in zircon, which would argue for the presence of $\mathrm{Ce}^{4+}$. Zircon/melt partitioning displays a small negative Eu anomaly. This is in line with the presence of some $\mathrm{Eu}^{2+}$, which preferentially enters the melt with respect to trivalent REE.

The determination of trace element partitioning at relatively low temperature is experimentally challenging, mainly because of the difficulties related to the creation of homogeneous crystals of sufficient size. All the experiments have been performed at $20 \mathrm{kbar}$ in order to obtain a large temperature interval where garnet, zircon and hydrous melt are present. We found that the desired assemblage was stable from $800^{\circ} \mathrm{C}$ to $1000^{\circ} \mathrm{C}$ at $20 \mathrm{kbar}$. It was determined that an initial heating step of $2 \mathrm{~h}$ at $1050{ }^{\circ} \mathrm{C}$ followed by cooling within $15 \mathrm{~min}$ to the desired temperature favoured the formation of a few, large garnet crystals (Fig. 1) with limited zoning. This initial heating step was adopted for all 
experiments relevant for garnet-melt partitioning. At $1050{ }^{\circ} \mathrm{C}$ garnet is not stable so that initial nucleation must have occurred during cooling. Small amounts of zircon, on the other hand, were stable at $1050{ }^{\circ} \mathrm{C}$ and acted as seeds. The small zircon crystals increased in grain size throughout cooling and equilibrated with the melt during the long experimental runs. In fact, examination of zircons with back-scattered electron (BSE) imaging did not reveal any significant zoning (Fig. 1c,d). The zircon crystals produced were less than $5 \mu \mathrm{m}$ across and thus difficult to analyse, but more likely to reach equilibrium with the melt. However, at the low temperatures of $750-850{ }^{\circ} \mathrm{C}$ there was clear evidence from the trace element composition that zircon did not completely equilibrate. Therefore, we performed two additional experiments at $800{ }^{\circ} \mathrm{C}$ and $850{ }^{\circ} \mathrm{C}$, without the heating step to $1050{ }^{\circ} \mathrm{C}$. These experiments produced much better zircon crystals but the garnet formed smaller crystals and displayed significant zoning in trace elements.

\subsection{Analytical techniques}

Phase relations in experimental charges were examined in polished mounts by back-scattered electron

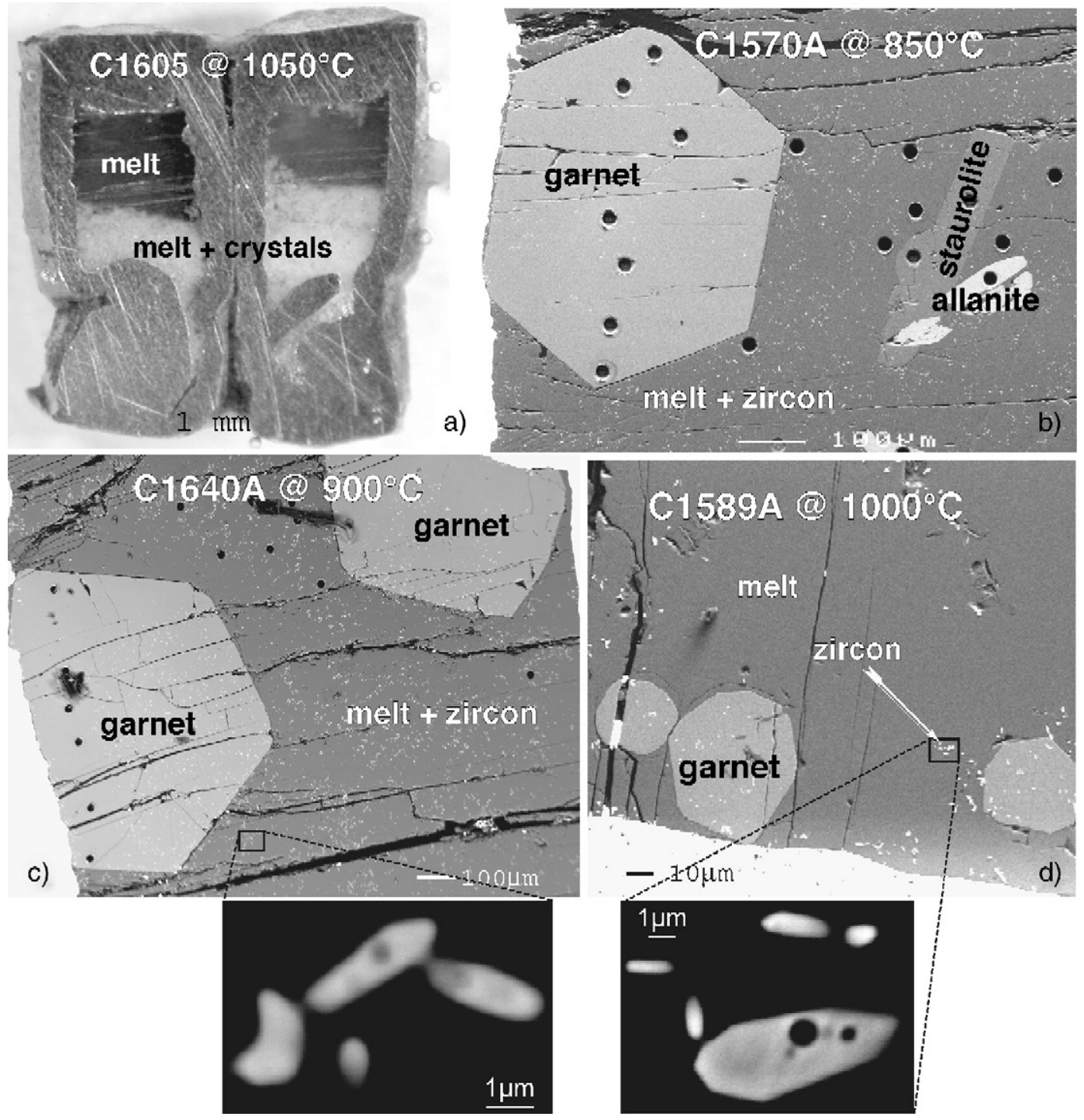

Fig. 1. Experimental runs: (a) Photomicrograph of double gold capsule. Note the gravity segregation of melt and crystals. (b-d) Back-scattered electron images of experimental runs conducted at different temperatures. Note the large euhedral garnet crystals in all experiments. The small, white crystals disseminated in the melt or as inclusions in garnet are zircon. Dark circles are laser pits from trace element analysis. Insets in $\mathrm{c}$ and $\mathrm{d}$ are highcontrast BSE images of zircon in the two experiments. The dark inclusion in zircon is either melt or Al-silicate. 
Table 2

Details of experimental runs and phases present

\begin{tabular}{|c|c|c|c|c|c|c|c|c|c|c|c|}
\hline Run & C1593B & C1587A & C1743 & $\mathrm{C} 1570 \mathrm{~A}$ & C1690A & C1245 & $\mathrm{C} 1640 \mathrm{~A}$ & $\mathrm{C} 1583 \mathrm{~A}$ & C1589A & $\mathrm{C} 2380$ & C1605A \\
\hline$T\left({ }^{\circ} \mathrm{C}\right)$ & $750^{\mathrm{a}}$ & $800^{\mathrm{a}}$ & 800 & $850^{\mathrm{a}}$ & 850 & $900^{\mathrm{a}}$ & $900^{\mathrm{a}}$ & $950^{\mathrm{a}}$ & 1000 & $1000^{\mathrm{a}}$ & 1050 \\
\hline$P$ (kbar) & 20 & 20 & 20 & 20 & 20 & 20 & 20 & 20 & 20 & 20 & 20 \\
\hline Hours & 427 & 162 & 169 & 190 & 260 & 322 & 228 & 163 & 164 & 50 & 165 \\
\hline Melt & $\mathrm{x}$ & $\mathrm{x}$ & $\mathrm{x}$ & $\mathrm{x}$ & $\mathrm{x}$ & $\mathrm{x}$ & $\mathrm{x}$ & $\mathrm{x}$ & $\mathrm{x}$ & $\mathrm{x}$ & $\mathrm{x}$ \\
\hline Grt & & $\mathrm{x}$ & $\mathrm{x}$ & $\mathrm{x}$ & $\mathrm{x}$ & $\mathrm{x}$ & $\mathrm{x}$ & $\mathrm{x}$ & $\mathrm{x}$ & $\mathrm{x}$ & \\
\hline Zrn & $\mathrm{x}$ & $\mathrm{x}$ & $\mathrm{x}$ & $\mathrm{x}$ & $\mathrm{x}$ & $\mathrm{x}$ & $\mathrm{x}$ & $\mathrm{x}$ & $\mathrm{x}$ & $\mathrm{x}$ & $\mathrm{x}$ \\
\hline Aln & $\mathrm{x}$ & $\mathrm{x}$ & $\mathrm{x}$ & $\mathrm{x}$ & $\mathrm{x}$ & $\mathrm{x}$ & $\mathrm{x}$ & & & & \\
\hline St & $\mathrm{x}$ & $\mathrm{x}$ & $\mathrm{x}$ & $\mathrm{x}$ & & & & $\mathrm{x}$ & & & \\
\hline Mica & $\mathrm{Bt}+\mathrm{Ph}$ & $\mathrm{Bt}$ & & & & & & & & & \\
\hline Opx & & & & $\mathrm{x}$ & & $\mathrm{x}$ & & & & & \\
\hline Ky or Crn & & & & & $\mathrm{x}$ & & $\mathrm{x}$ & & $\mathrm{x}$ & $\mathrm{x}$ & $\mathrm{x}$ \\
\hline
\end{tabular}

Grt: garnet; Zrn: zircon; Aln: allanite; St: staurolite; Bt: biotite; Ph: phengite; Opx: orthopyroxene; Ky: kyanite; Crn: corundum.

${ }^{a}$ With initial $2 \mathrm{~h}$ heating step at $1050^{\circ} \mathrm{C}$.

images on a JEOL 6400 SEM (Electron Microscopy Unit, ANU). The phase compositions of experimental runs were determined by energy dispersive spectrometry (EDS), employing an accelerating voltage of $15 \mathrm{kV}$ and a beam current of $1 \mathrm{nA}$. Melt composition was obtained using EDS by scan analysis of areas bigger than $5 \times 5 \mu \mathrm{m}$. Monitoring the $\mathrm{Na}_{2} \mathrm{O}$ and $\mathrm{K}_{2} \mathrm{O}$ count rates during analyses showed that with this set-up no $\mathrm{Na}$ and $\mathrm{K}$ loss occurred during analyses. Consequently the $\mathrm{H}_{2} \mathrm{O}$ content of the glasses can be estimated from the oxide totals of the melt analyses (Devine et al., 1995).

Trace element concentrations were determined by LA-ICP-MS at the Research School of Earth Sciences (ANU) using a pulsed $193 \mathrm{~nm}$ ArF Excimer laser with $100 \mathrm{~mJ}$ energy at a repetition rate of $5 \mathrm{~Hz}$ (Eggins et al., 1998) coupled to an Agilent 7500 quadrupole ICP-MS. Laser sampling was performed in an $\mathrm{He}-\mathrm{Ar}$ atmosphere using a small spot size of 19,23 or $32 \mu \mathrm{m}$ diameter. Data acquisition was performed by peak hopping in pulse counting mode, acquiring individual intensity data for each element during each mass spectrometer sweep. A total of 70 to 80 sweeps, comprising a gas background of 20-25 sweeps, were performed for each analysis. During the time-resolved analysis, contamination was detected by monitoring several elements (Fig. 2) and only the relevant part of the signal was integrated. A synthetic glass (NIST 612) was used as standard material and values were taken from Pearce et al. (1997). Internal standard was $\mathrm{CaO}$ measured by electron microprobe.

The large size of the experimentally produced garnet and melt pockets (Fig. 1) made it possible to easily analyse their trace element compositions by LA-ICP-MS. Detailed BSE images revealed that tiny zircons were disseminated through the garnet grains. In most cases it was possible to avoid these micro inclusions. When zircon inclusions were sampled during garnet analysis, the time resolved counts of elements that strongly partition into zircon such as $\mathrm{Zr}$, Hf, Th and $\mathrm{U}$ helped to distinguish between clean garnet and garnet+zircon mixtures (Fig. 2a).

Direct measurement of single zircon trace element composition was not possible because the grain size of

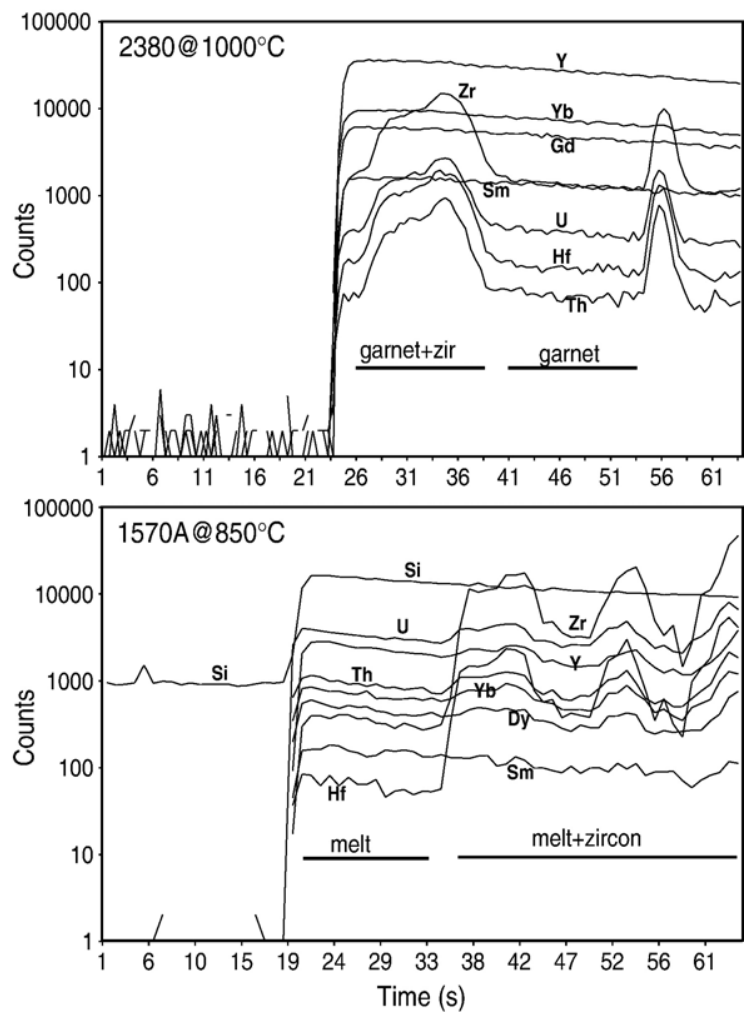

Fig. 2. LA-ICP-MS analysis of garnet and melt with zircon inclusions. Note the steep count increase between the background and when the laser is turned on. A dramatic compositional difference allows separating the part of the signal representing pure melt or garnet from those where zircon inclusions are present. 
zircon was always smaller than the LA-ICP-MS pit. This analytical problem was solved by measuring zircon-melt mixes (Fig. 2b) with various proportions of the two components and regressing to the zircon end-member. The $\mathrm{CaO}$ content of the glass was adopted as the internal standard for the mixed analyses because the proportion of zircon was always much less than that of glass. The various analyses were plotted in a $\mathrm{Zr}$ versus another trace element diagram to define a regression line (Fig. 3a). Excellent correlation coefficients $(R>0.95)$ were obtained for trace elements compatible in zircon such as $\mathrm{Y}$ and $\mathrm{Yb}$. With partition coefficients approaching unity, the quality of regression decreased. The values for element with an $R$ below 0.75 were discarded. The trace elements composition of zircon was obtained by regressing to the $\mathrm{Zr}$ content of zircon, which was between 41 and $45 \mathrm{wt} . \% \mathrm{Zr}$ according to the amount of trace element substituting for $\mathrm{Zr}$.

A number of tests have been performed to assess the validity of this approach. 1) A mix containing $20 \%$ of zircon powder from a large homogeneous gem-quality zircon from Queensland and $80 \%$ of a haplogranitic synthetic composition free of trace elements was melted on a $0.3 \mathrm{~mm}$-thick molybdenum strips under 5 bars of argon pressure. Fusion of the rock powders was obtained by passing current of up to $8 \mathrm{~A}$ through the molybdenum strips. As soon as the powder melted rapid quenching was achieved by simultaneously turning off the current and dropping the argon pressure to 1 bar. During the very short time of melting, zircon was unable to react with the haplogranite and thus remained as fragments in the glass. Mixed zircon-melt analyses with zircon being between 1-5\% were regressed as described above for the experiments (Fig. 3b). The calculated composition for zircon was within error (within 3 to $15 \%)$ the same of what was measured for the initial zircon, even at this low zircon percent and at the low trace element amount measured $(<5 \mathrm{ppm}$ for HREE, Fig. 3c). 2) Regression between $\mathrm{Zr}$ and $\mathrm{U}$, Th and $\mathrm{Hf}$ (elements which most differ in concentration between garnet and zircon) were also calculated for garnetzircon mixes in two experiments $\left(1640 \mathrm{~A} @ 900{ }^{\circ} \mathrm{C}\right.$ and
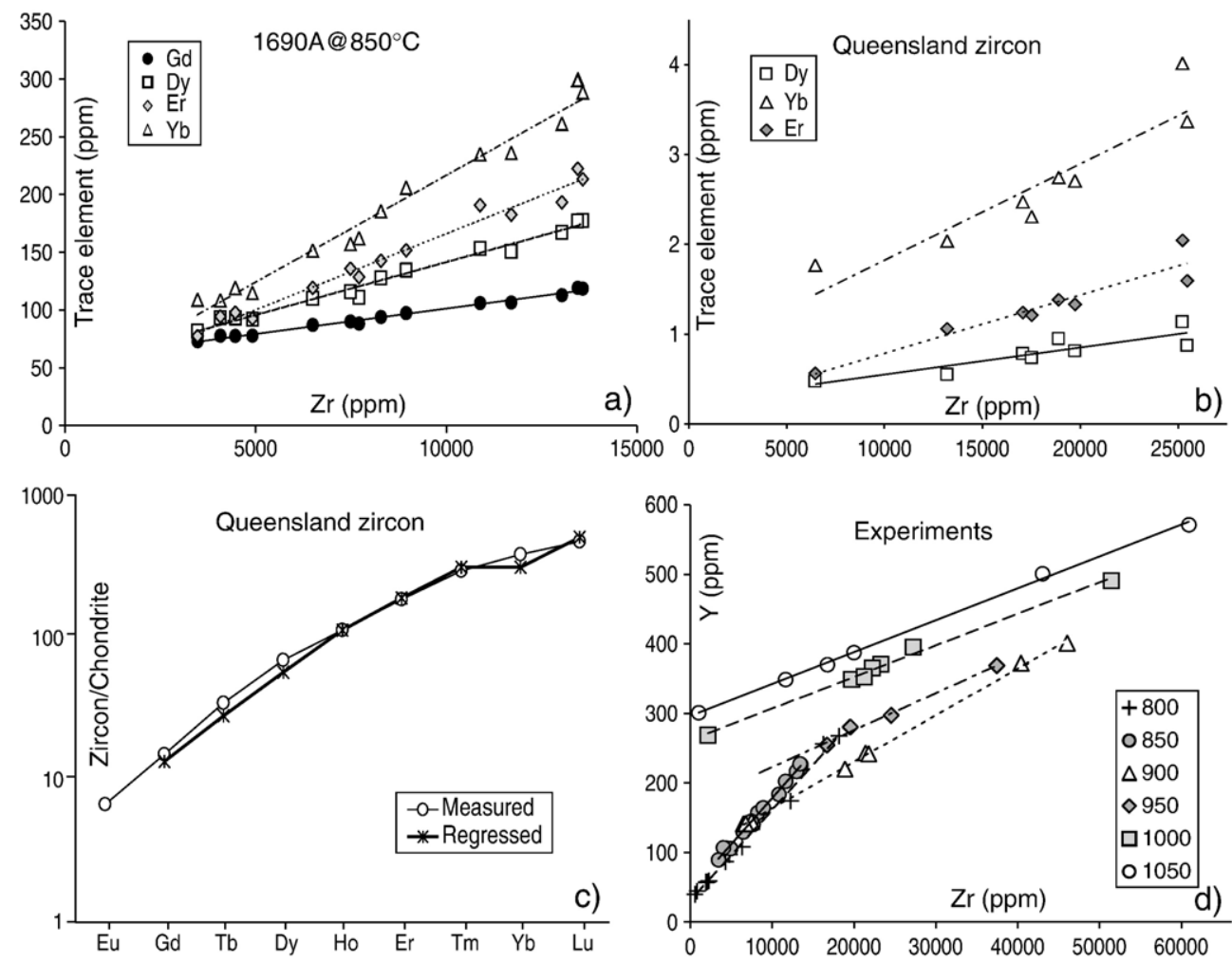

Fig. 3. Analytical method to determine zircon composition. a) Regression between $\mathrm{Zr}$ and other trace elements for mixed melt-zircon analyses in experiment1690A@850 ${ }^{\circ} \mathrm{C}$. b) Regression between $\mathrm{Zr}$ and other trace elements for mixed melt-zircon analyses for a Queensland zircon of known composition. c) Comparison between the measured and calculated (via regression of mixed melt-zircon analyses) trace element pattern of a zircon of know composition from Queensland. d) Regression between $\mathrm{Zr}$ and $\mathrm{Y}$ for experiments at different $T$. Errors in all diagrams are smaller than symbols. See Section 2.3. for additional explanation. 
2380@1000 ${ }^{\circ} \mathrm{C}$ ) and extrapolated to the $\mathrm{Zr}$ content in zircon. For each experiment, the $\mathrm{U}, \mathrm{Th}$ and $\mathrm{Hf}$ concentrations obtained with the garnet regression were comparable to those obtained with the zirconmelt mixes. This calculation also indicates that zircon included in garnet has similar composition to that in the melt and thus equilibrium was reached. 3) Zircon included in staurolite was measured in experiment $1583 @ 950{ }^{\circ} \mathrm{C}$. Because staurolite is virtually free of trace elements $(<1 \mathrm{ppm}$ for all elements excluding $\mathrm{P})$ mixed zircon staurolite analyses could be extrapolated to $\mathrm{Zr}$ content in zircon. The zircon composition obtained for the M-HREE, Y, Hf, Th and U are identical to those obtained with the zircon-melt regression. 4) Plotting Y against $\mathrm{Zr}$ for all experiments allows an assessment of whether the applied regression is able to distinguish between zircon compositions produced in the different experiments. Fig. 3d shows that there is a significant difference between the regressions at different temperatures. This indicates that the results obtained for the different temperatures are distinguishable. These four tests provide evidence that, for the experiments, the zircon composition obtained from the regression is reliable and accurate regardless of the relatively small percent of zircon in the mixed analyses. Apart from zircon, melt and garnet, the only other trace element rich phase present in some experiments was allanite. Contamination from allanite during zircon-melt analysis was easily detected because of high LREE and Th counts and such analyses were discarded. The presented data include only analyses where the trace element contents derive from a binary zircon-melt mixture.

Some of the zircon produced contained high levels of trace elements. This unusual composition was confirmed by electron microprobe using a Cameca SX100 employing a probe current of $20 \mathrm{nA}$ and an accelerating voltage of $25 \mathrm{kV}$. Counting times on $\mathrm{Y} \mathrm{L} \alpha, \mathrm{Zr} \mathrm{L} \alpha, \mathrm{Yb} \mathrm{L} \alpha$, Th $\mathrm{M} \alpha, \mathrm{U}$ $\mathrm{M} \alpha, \mathrm{P} \mathrm{K} \alpha$ and Si K $\alpha$ were between 20 and 40 s. The size of the zircon crystals was too small to obtain clean analyses even by electron microprobe; the results reported in the table are the average of 9-10 analyses with 50 to $80 \%$ zircon and 50 to $20 \%$ melt, from which the melt composition was subtracted. Garnet was also analysed for major and some trace elements $(\mathrm{P}, \mathrm{Y}$ and $\mathrm{Yb})$ by electron microprobe using a Cameca SX100 with a focused beam, and employing a probe current of $20 \mathrm{nA}$ and an accelerating voltage of $15 \mathrm{kV}$. Standards for P, Y and $\mathrm{Yb}$ were $\mathrm{CaPO}, \mathrm{YP}_{5} \mathrm{O}_{14}$ and $\mathrm{YbPO}$, respectively. Profiles consisting of 40 to 50 analyses were measured across large garnet crystals.

LA-ICP-MS analysis samples a much larger volume with respect to EMP analysis, and each laser analysis represents the average composition of a large number of zircon crystals. This approach is considered to be more accurate and less affected by potential variations in single zircon composition. Therefore the concentrations obtained by LA-ICP-MS are preferred and used for the calculation of partitioning. Another advantage of using LA-ICP-MS for melt, zircon and garnet compositions is that all three are compared to the same standard and hence, in the partitioning, uncertainties related to the standard are cancelled out. It is important to note that for a correlation such as shown in Fig. 3a, the error on the precision is relevant. This error is only about $2-3 \%$ as demonstrated by multiple analyses of standards. Hence, the errors on single measurements are generally smaller than the symbols shown in Fig. 3 and do not affect the correlation. The error on the regressed trace element value is calculated using the Excel 98 Data Analysis package, and represents the error on the correlation only, without attributing errors to the single measurements. Practically, we mirrored the $\mathrm{Zr}$ composition $\left(\mathrm{Zr}=\mathrm{Zr}_{\text {zircon }}-\mathrm{Zr}_{\text {measured }}\right)$ and then calculated the intercept with the $Y$-axis and the associated 1 sigma uncertainty. The 1 sigma errors on the zircon trace element composition are mostly below $10 \%$ and always below $20 \%$, with the only exception of $\mathrm{P}$ in two experiments (22 and 24\%). These uncertainties are common for trace element geochemistry, and were propagated to the calculation of distribution coefficients.

In experiment $1690 \mathrm{~A}$, a small amount $(<0.5 \%)$ of zircon contamination hampered the measurement of MREE, HREE, Zr, Hf, Th and U contents in the melt. The concentration of these elements in the experiment was obtained by regressing melt-zircon analyses to $\mathrm{Zr}=133 \mathrm{ppm}$, as measured in a similar experiment run at identical conditions. For Ba and LREE the value given is that of the direct measurement, because such a small zircon contamination has no effect on these elements.

\section{Run products}

The textures in the experimental runs were investigated by optical microscopy and back-scattered electron imaging (see phases in Table 2). In most of the experiments, particularly at higher temperatures, gravity segregation occurred: the melt concentrated at the top of the capsule, whereas crystals were more abundant at the bottom (Fig. 1a). Melt is the most abundant phase in all experiments with $70-90 \%$ in volume. In experiments with the heating step at $1050{ }^{\circ} \mathrm{C}$, garnet occurs as a few, euhedral crystals that are several $100 \mu \mathrm{m}$ in diameter (Fig. 1a-d), whereas in experiment 1743@800 ${ }^{\circ} \mathrm{C}$ and 1690A@850 ${ }^{\circ} \mathrm{C}$ garnet crystals are smaller. Zircon is always present and forms small, elongated $(<10-5 \mu \mathrm{m}$ 
long, $<5 \mu \mathrm{m}$ wide) crystals throughout the melt and as inclusions in all the solid phases (Fig. 1b-d). Zircon contains micro inclusions of melt or kyanite. Other phases such as staurolite, allanite and biotite, occur at a very low abundance and are generally euhedral and variable in size (Fig. 1b), from 20 to hundreds of microns in length. Accessory allanite is present in the lower temperature runs at 750 to $900{ }^{\circ} \mathrm{C}$. Staurolite is present at $750{ }^{\circ} \mathrm{C}, 800{ }^{\circ} \mathrm{C}$, in one of the runs at $850{ }^{\circ} \mathrm{C}$ and in the experiment at $950{ }^{\circ} \mathrm{C}$. Biotite occurs as a minor mineral at $800{ }^{\circ} \mathrm{C}$ whereas relatively abundant biotite and phengite are present at $750{ }^{\circ} \mathrm{C}$. Minor orthopyroxene was observed in one of the runs at 850 and at $900{ }^{\circ} \mathrm{C}$. Kyanite and occasionally corundum appears at temperatures $\geq 850{ }^{\circ} \mathrm{C}$ to accommodate the aluminium in excess. Equilibrium textures are observed in all experiments.

\section{Phase composition}

\subsection{Major elements}

The experiments produced peraluminous granitic melts with an alumina saturation index $[\mathrm{ASI}=\mathrm{Al} /(\mathrm{K}+\mathrm{Na}+2 \mathrm{Ca})$ expressed in molar fraction] between 1.15 and 1.49 (Table 3). The melt shows a moderate trend to more mafic compositions at higher temperature with increasing in $\mathrm{MgO}$ and $\mathrm{FeO}$ contents (Fig. 4a). The measured totals of 84-89 wt.\% oxides indicate that the melts contain additional about $11-16$ wt. $\%$ of $\mathrm{H}_{2} \mathrm{O}$, in agreement with mass balance having 11 wt. $\%$ of $\mathrm{H}_{2} \mathrm{O}$ in the starting material and $70-90 \%$ melt in the experiments. Compositional variations in experiments run at identical conditions are due to some difference in the starting material and different proportions of phases. No significant heterogeneity was detected within a single experiment, as indicated by the low error on the average of multiple analyses (Table 3).

Within each experiment, garnet is relatively homogeneous in major elements (Table 4). Garnet crystals as large as $500-800 \mu \mathrm{m}$ show variation of maximum $20 \%$ in major elements from core to rim (Fig. 5). EDS and WDS analyses were performed along one or more profiles across the garnet crystals and the small standard deviation on multiple analyses reported in Table 4 testifies to the homogeneity of garnet. With increasing temperature, there is a systematic increase in the pyrope component of garnet (Py $25 @ 800{ }^{\circ} \mathrm{C}-\mathrm{Py}_{44} @ 1000{ }^{\circ} \mathrm{C}$, Table 4, Fig. 4a), whereas the grossular component decreases $\left(\mathrm{Gr}_{22} @ 800{ }^{\circ} \mathrm{C}-\mathrm{Gr}_{8} @ 1000{ }^{\circ} \mathrm{C}\right)$. Normalisation of the garnets including also the measured trace elements indicates that only a small amount of $\mathrm{Fe}^{3+}$ of less then
$5 \%$ of the total iron is required to obtain charge balance. An interesting feature of the experiments is the observed change of $\mathrm{Mg} \#\left(\mathrm{Mg} /\left(\mathrm{Mg}+\mathrm{Fe}^{2+}\right)\right)$ of garnet relative to melt (Fig. 4a). At 800 to $900{ }^{\circ} \mathrm{C}$ garnet has a lower $\mathrm{Mg} \#$ than the melt, at $950{ }^{\circ} \mathrm{C}$ it is identical and at $1000{ }^{\circ} \mathrm{C}$ garnet has a higher $\mathrm{Mg} \#$ than melt. Therefore, garnetproducing partial melting of felsic rocks at low temperature will generate a restite that has a significantly lower $\mathrm{Mg} \#$ and a melt that has a higher Mg\# than the protolith.

\subsection{Trace elements}

Accessory phases such as staurolite, kyanite and corundum were analysed for trace elements using LAICPMS. They were found not to contain significant amounts of trace elements and, thus, they are not further discussed. Allanite is rich in LREE and Th, but its presence does not significantly affect the HREE partitioning between garnet, melt and zircon, which is the main focus of this paper.

\subsubsection{Melt}

The trace element composition of the melt within each experiment is homogeneous (Table 3). The $\mathrm{Ba}$ content of the melts is slightly higher than in the starting material indicating that the experiments contained high amounts of melt $(>80 \%)$. The small decrease of Ba with increasing $T$ is related to an increase in melt volume (Fig. 4b). Apart from $\mathrm{Ba}$, a general increase of trace elements in the melt is observed with increasing $T$ (Table 3 and Fig. 4b). The most systematic change in concentration is observed in $\mathrm{Zr}$ because the melts are buffered with zircon over the whole temperature range. This systematic change provides good evidence that the melts attained trace element equilibrium. Hf shows a similar correlation to $\mathrm{Zr}$, although the increase is less pronounced. Therefore $\mathrm{Hf} / \mathrm{Zr}$ decreases with increasing temperature from $0.10-0.14$ at $750-800{ }^{\circ} \mathrm{C}$ to 0.068 at $1050{ }^{\circ} \mathrm{C}$, which is close to the value of 0.067 of the starting material. This indicates that the presence of zircon is able to fractionate $\mathrm{Zr}$ and $\mathrm{Hf}$ in experimental melts, especially at low temperatures. In natural rocks, it is expected that crystallization of zircon at low temperatures can produce granitic melts with low $\mathrm{Zr} / \mathrm{Hf}$.

\subsubsection{Garnet}

Most garnet cross sections that were analysed show limited zoning in trace elements (Table 4, Fig. 5). Detailed profiles of large garnets (experiments at 800 and $900{ }^{\circ} \mathrm{C}$ ) measured by electron microprobe indicated a certain variation in $\mathrm{Y}$ content, with 1 sigma errors in the order of $17-25 \%$ without any particular trend from 
Table 3

Major (in wt. $\% \pm 1 \sigma$ S.D.) and trace (in ppm $\pm 1 \sigma$ S.D.) element composition of the melt

\begin{tabular}{|c|c|c|c|c|c|c|c|c|c|c|c|c|c|c|c|c|c|c|c|c|c|c|}
\hline \multirow{2}{*}{$\begin{array}{l}\text { Run no. } \\
T-P \\
\end{array}$} & \multirow{2}{*}{\multicolumn{2}{|c|}{$\frac{1593 \mathrm{~B}}{750^{\mathrm{a}}-20}$}} & \multirow{2}{*}{\multicolumn{2}{|c|}{$\frac{1587 \mathrm{~A}}{800^{\mathrm{a}}-20}$}} & \multirow{2}{*}{\multicolumn{2}{|c|}{$\frac{1743}{800-20}$}} & \multirow{2}{*}{\multicolumn{2}{|c|}{$\frac{1570 \mathrm{~A}}{850^{\mathrm{a}}-20}$}} & \multirow{2}{*}{\multicolumn{2}{|c|}{$\frac{1690 \mathrm{~A}}{850-20}$}} & \multirow{2}{*}{\multicolumn{2}{|c|}{$\frac{1245}{900^{\mathrm{a}}-20}$}} & \multirow{2}{*}{\multicolumn{2}{|c|}{$\frac{1640 \mathrm{~A}}{900^{\mathrm{a}}-20}$}} & \multirow{2}{*}{\multicolumn{2}{|c|}{$\frac{1583 \mathrm{~A}}{950^{\mathrm{a}}-20}$}} & \multirow{2}{*}{\multicolumn{2}{|c|}{$\frac{1589 \mathrm{~A}}{1000-20}$}} & \multirow{2}{*}{\multicolumn{2}{|c|}{$\frac{2380}{1000^{\mathrm{a}}-20}$}} & \multirow{2}{*}{\multicolumn{2}{|c|}{$\frac{1605 \mathrm{~A}}{1050-20}$}} \\
\hline & & & & & & & & & & & & & & & & & & & & & & \\
\hline \multirow[t]{2}{*}{ No. of analysis } & \multicolumn{2}{|c|}{6} & \multicolumn{2}{|l|}{3} & \multicolumn{2}{|l|}{5} & \multicolumn{2}{|c|}{3} & \multicolumn{2}{|c|}{8} & \multicolumn{2}{|l|}{7} & 4 & & 3 & & 3 & & 7 & & 3 & \\
\hline & wt.\% & $\pm 1 \sigma$ & wt.\% & $\pm 1 \sigma$ & wt.\% & $\pm 1 \sigma$ & wt.\% & $\pm 1 \sigma$ & wt.\% & $\pm 1 \sigma$ & wt.\% & $\pm 1 \sigma$ & wt.\% & $\pm 1 \sigma$ & wt.\% & $\pm 1 \sigma$ & wt.\% & $\pm 1 \sigma$ & wt.\% & $\pm 1 \sigma$ & wt.\% & $\pm 1 \sigma$ \\
\hline $\mathrm{SiO}_{2}$ & 61.26 & 0.35 & 61.63 & 0.22 & 61.02 & 0.33 & 60.11 & 0.20 & 63.90 & 0.46 & 62.47 & 0.63 & 58.98 & 0.11 & 60.23 & 0.57 & 56.73 & 0.19 & 62.14 & 0.21 & 54.94 & 0.21 \\
\hline $\mathrm{Al}_{2} \mathrm{O}_{3}$ & 13.12 & 0.13 & 12.99 & 0.08 & 13.88 & 0.11 & 13.53 & 0.19 & 13.25 & 0.29 & 13.10 & 0.11 & 14.30 & 0.07 & 14.77 & 0.61 & 15.57 & 0.14 & 15.31 & 0.13 & 15.86 & 0.11 \\
\hline $\mathrm{FeO}$ & 1.33 & 0.13 & 1.55 & 0.13 & 0.92 & 0.08 & 1.77 & 0.11 & 0.60 & 0.13 & 1.29 & 0.08 & 1.38 & 0.06 & 2.82 & 0.15 & 3.49 & 0.11 & 2.58 & 0.11 & 3.51 & 0.09 \\
\hline $\mathrm{MgO}$ & 0.45 & 0.05 & 0.57 & 0.03 & 0.64 & 0.06 & 0.85 & 0.08 & 0.42 & 0.03 & 0.56 & 0.04 & 0.78 & 0.07 & 1.27 & 0.23 & 1.67 & 0.01 & 1.02 & 0.05 & 1.75 & 0.04 \\
\hline $\mathrm{CaO}$ & 2.51 & 0.06 & 2.63 & 0.01 & 2.34 & 0.02 & 2.52 & 0.10 & 1.64 & 0.08 & 1.93 & 0.08 & 2.50 & 0.13 & 2.50 & 0.17 & 2.68 & 0.09 & 2.79 & 0.08 & 2.52 & 0.04 \\
\hline $\mathrm{Na}_{2} \mathrm{O}$ & 2.26 & 0.19 & 1.94 & 0.34 & 1.97 & 0.14 & 2.14 & 0.20 & 2.74 & 0.08 & 2.30 & 0.15 & 1.83 & 0.33 & 1.87 & 0.32 & 1.71 & 0.54 & 2.16 & 0.21 & 2.01 & 0.10 \\
\hline $\mathrm{K}_{2} \mathrm{O}$ & 2.15 & 0.04 & 2.58 & 0.04 & 3.18 & 0.11 & 3.05 & 0.14 & 3.76 & 0.09 & 3.51 & 0.10 & 3.01 & 0.06 & 2.86 & 0.19 & 2.55 & 0.11 & 3.05 & 0.04 & 2.56 & 0.10 \\
\hline Total & 83.07 & 0.95 & 83.90 & 0.27 & 83.95 & 0.67 & 83.97 & 0.18 & 86.31 & 0.50 & 85.15 & 0.60 & 82.77 & 0.30 & 86.31 & 0.42 & 84.41 & 0.44 & 89.1 & 0.32 & 83.15 & 0.48 \\
\hline $\mathrm{H}_{2} \mathrm{O}^{\mathrm{b}}$ & 15 & & 14 & & 14 & & 13 & & 13 & & 13 & & 12 & & 12 & & 12 & & 11 & & 11 & \\
\hline $\mathrm{ASI}^{\mathrm{c}}$ & 1.24 & & 1.21 & & 1.27 & & 1.19 & & 1.15 & & 1.18 & & 1.32 & & 1.38 & & 1.49 & & 1.28 & & 1.49 & \\
\hline $\mathrm{Mg}^{\mathrm{d}}$ & 0.38 & & 0.39 & & 0.55 & & 0.46 & & 0.55 & & 0.44 & & 0.50 & & 0.44 & & 0.46 & & 0.41 & & 0.47 & \\
\hline No. of analysis & 3 & & 3 & & 4 & & 2 & & $14^{\mathrm{e}}$ & & 4 & & 4 & & 3 & & 5 & & 7 & & 7 & \\
\hline & ppm & $\pm 1 \sigma$ & ppm & $\pm 1 \sigma$ & ppm & $\pm 1 \sigma$ & ppm & $\pm 1 \sigma$ & ppm & $\pm 1 \sigma$ & $\mathrm{ppm}$ & $\pm 1 \sigma$ & $\mathrm{ppm}$ & $\pm 1 \sigma$ & ppm & $\pm 1 \sigma$ & ppm & $\pm 1 \sigma$ & ppm & $\pm 1 \sigma$ & $\mathrm{ppm}$ & $\pm 1 \sigma$ \\
\hline$P$ & 785 & 18 & 577 & 33 & 815 & 64 & 710 & 122 & - & - & 63 & 3 & 952 & 90 & 656 & 30 & 1032 & 104 & 1247 & 107 & 960 & 14 \\
\hline Y & 14.6 & 0.4 & 68 & 1 & 36 & 1 & 113 & 1 & 46 & 3 & 43 & 2 & 101 & 3 & 246 & 4 & 265 & 3 & 161 & 2 & 301 & 5 \\
\hline $\mathrm{Zr}$ & 62 & 6 & 92 & 1 & 82 & 2 & 133 & 6 & - & - & 159 & 1 & 178 & 5 & 329 & 6 & 566 & 5 & 428 & 5 & 841 & 9 \\
\hline $\mathrm{Ba}$ & 318 & 7 & 382 & 11 & 418 & 8 & 399 & 12 & 485 & 12 & 415 & 7 & 366 & 11 & 354 & 6 & 349 & 6 & 400 & 3 & 335 & 4 \\
\hline $\mathrm{La}$ & 0.53 & 0.05 & 1.9 & 0.2 & 42 & 2 & 33 & 2 & 53 & 2 & 61 & 3 & 291 & 7 & 326 & 6 & 327 & 4 & 369 & 3 & 308 & 4 \\
\hline $\mathrm{Ce}$ & 0.52 & 0.09 & 1.6 & 0.1 & 40 & 1 & 30 & 2 & 51 & 3 & 60 & 3 & 286 & 9 & 338 & 8 & 335 & 3 & 374 & 2 & 315 & 3 \\
\hline $\operatorname{Pr}$ & 0.22 & 0.26 & 1.5 & 0.1 & 39 & 2 & 28 & 1 & 47 & 2 & 59 & 2 & 280 & 6 & 324 & 5 & 325 & 4 & 361 & 4 & 306 & 4 \\
\hline $\mathrm{Nd}$ & 0.65 & 0.04 & 1.3 & 0.1 & 45 & 3 & 30 & 1 & 48 & 2 & 62 & 2 & 283 & 10 & 330 & 5 & 333 & 7 & 366 & 2 & 309 & 4 \\
\hline Sm & 0.67 & 0.16 & 3.0 & 0.1 & 66 & 3 & 40 & 2 & 56 & 2 & 59 & 2 & 242 & 10 & 306 & 7 & 315 & 1 & 333 & 3 & 303 & 6 \\
\hline Eu & 2.8 & 0.1 & 16 & 2 & 107 & 4 & 77 & 2 & 92 & 2 & 44 & 1 & 249 & 6 & 296 & 8 & 306 & 4 & 327 & 2 & 297 & 4 \\
\hline Gd & 1.3 & 0.3 & 8.0 & 0.4 & 64 & 2 & 50 & 2 & 58 & 1 & 48 & 2 & 165 & 5 & 264 & 5 & 285 & 4 & 250 & 3 & 282 & 3 \\
\hline Dy & 4.7 & 0.4 & 34 & 1 & 37 & 1 & 79.2 & 0.1 & 51 & 3 & 40 & 1 & 107 & 3 & 242 & 5 & 266 & 5 & 178 & 2 & 284 & 4 \\
\hline Er & 20 & 1 & 74 & 3 & 25 & 1 & 106.4 & 0.0 & 36 & 5 & 36 & 2 & 73 & 1 & 218 & 3 & 217 & 5 & 121 & 2 & 273 & 4 \\
\hline $\mathrm{Yb}$ & 55 & 2 & 111 & 3 & 22 & 2 & 135 & 2 & 34 & 8 & 39 & 2 & 61 & 1 & 215 & 5 & 184 & 7 & 100 & 1 & 268 & 4 \\
\hline $\mathrm{Lu}$ & 65 & 4 & 119 & 1 & 20 & 1 & 138 & 2 & 29 & 7 & 38 & 1 & 55 & 2 & 205 & 4 & 161 & 5 & 88 & 1 & 256 & 3 \\
\hline $\mathrm{Hf}$ & 6.3 & 1.2 & 11 & 1 & 9 & 1 & 13.8 & 0.4 & - & - & 11.8 & 0.1 & 14 & 1 & 27 & 1 & 41 & 1 & 32 & 0 & 57 & 1 \\
\hline Th & 0.53 & 0.14 & 7.6 & 1.6 & 151 & 6 & 57.3 & 0.2 & 111 & 6 & 112 & 4 & 294 & 7 & 317 & 5 & 331 & 2 & 363 & 4 & 331 & 2 \\
\hline $\mathrm{U}$ & 19 & 1 & 99 & 3 & 110 & 7 & 193 & 1 & 118 & 28 & 199 & 2 & 308 & 10 & 331 & 7 & 341 & 5 & 357 & 3 & 369 & 3 \\
\hline $\mathrm{Hf} / \mathrm{Zr}$ & 0.10 & 0.03 & 0.12 & 0.04 & 0.10 & 0.02 & 0.10 & 0.01 & & & 0.074 & 0.001 & 0.079 & 0.007 & 0.082 & 0.004 & 0.072 & 0.002 & 0.075 & 0.002 & 0.068 & 0.002 \\
\hline $\mathrm{Th} / \mathrm{U}$ & 0.03 & 0.01 & 0.08 & 0.02 & 1.38 & 0.15 & 0.297 & 0.002 & 0.94 & 0.22 & 0.56 & 0.02 & 0.95 & 0.05 & 0.96 & 0.03 & 0.97 & 0.02 & 1.02 & 0.02 & 0.90 & 0.01 \\
\hline
\end{tabular}

$=$ not given because of poor regression $(R<0.750)$

${ }^{a}$ With initial $2 \mathrm{~h}$ heating step at $1050{ }^{\circ} \mathrm{C}$.

${ }^{b}$ Estimated $\mathrm{H}_{2} \mathrm{O}$ content from mass balance.

c $\mathrm{ASI}=\mathrm{Al} /(\mathrm{Na}+\mathrm{K}+2 \times \mathrm{Ca})$ in molar fraction

${ }^{\mathrm{d}} \mathrm{Mg} /\left(\mathrm{Mg}+\mathrm{Fe}^{2+}\right)$.

e Composition of MREE, HREE Th and U calculated using a linear regression between melt and zircon. 
core to rim. A larger variation was observed in a large garnet in run 1570@850 ${ }^{\circ} \mathrm{C}$, which displays a core richer in $\mathrm{Y}$ than the rim. In this case, LA-ICPMS analyses from the garnet rim, the part of the crystal that is in textural equilibrium with the surrounding melt, were used for calculation of trace element partitioning. The EMP profiles demonstrate that the rim is large enough to get clean LA-ICPMS analyses that are not affected by the HREE-rich core. There is a good agreement between the $\mathrm{Y}$ content of the garnet rim obtained from multiple LA-ICPMS analyses with the value obtained from EMP profiles.

As expected, garnet strongly fractionates the REE and is rich in HREE and poor in LREE. Similarly to the melt, the $\mathrm{Zr}$ content of garnet is buffered by zircon. Analysis of $\mathrm{Zr}$ in garnet requires great care as zircon inclusions can bias correct laser ablation analyses. We checked carefully the time-resolved analysis for $\mathrm{Zr}$ spikes resulting from inclusions (Fig. 2a), and integrated only the clean part of the signal. The results show that the $\mathrm{Zr}$ content in garnet
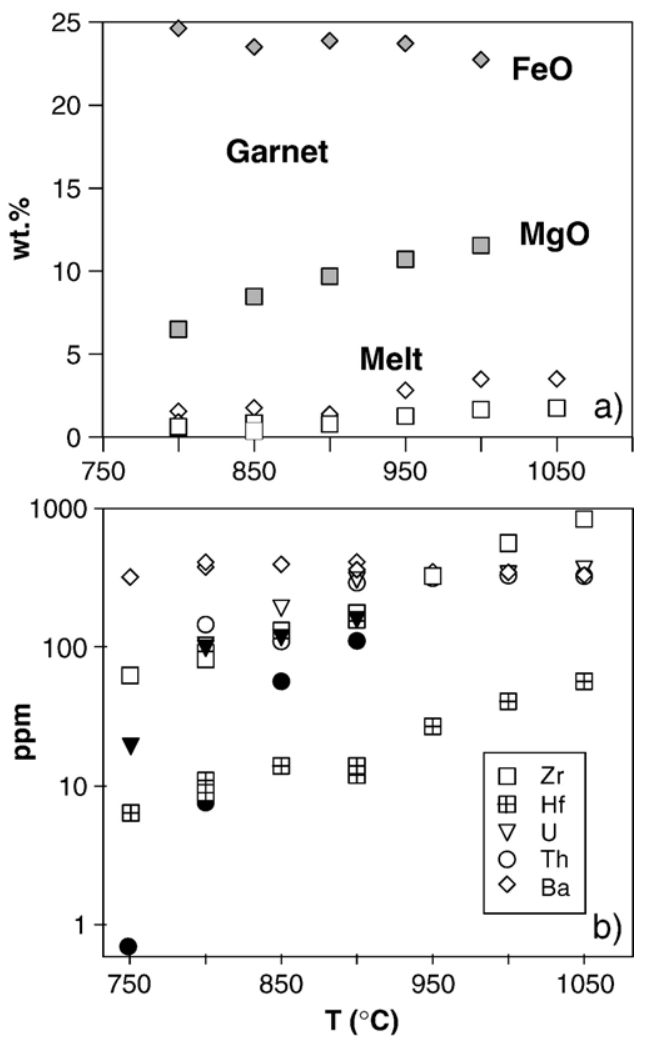

Fig. 4. Composition of melt and garnet. a) Garnet and melt $\mathrm{FeO}$ and $\mathrm{MgO}$ composition in wt.\% at different temperatures. Filled symbols indicate garnet and open symbols indicate melt. b) Variation of trace element composition of the melt with temperature. Filled symbols are for Th and $\mathrm{U}$ contents in experiments containing significant amounts of allanite. increases from $200 \mathrm{ppm}$ at $800{ }^{\circ} \mathrm{C}$ to $814 \mathrm{ppm}$ at $1000^{\circ} \mathrm{C}$. The regular behaviour of $\mathrm{Zr}$ in garnet is good evidence that the trace elements in garnet attained equilibrium. There is an increase in phosphorus and HREE content with decreasing temperature. Garnet incorporates significantly more $\mathrm{U}$ than $\mathrm{Th}$ with a $\mathrm{Th} / \mathrm{U}$ below 0.2 for all experiments. Two experiments were performed at $850^{\circ} \mathrm{C}$ : run $1570 \mathrm{~A}$ had the heating step at $1050{ }^{\circ} \mathrm{C}$ and produced large garnets, whereas run $1690 \mathrm{~A}$ with no initial heating step produced small garnets rich in zircon inclusions. In this last experiment, the garnet trace element composition can be obtained by subtracting the contribution of minor zircon contamination by a correlation method of garnetzircon mixed analyses. The values of $D^{\text {Grt/Melt }}$ obtained using this calculated garnet composition are similar to those directly determined by measuring melt and garnet in the experiment $1570 \mathrm{~A} @ 850{ }^{\circ} \mathrm{C}$ : the two results are within $25 \%$ for the HREE and within $40 \%$ for the MREE. This provides evidence that the large garnet rims observed in experiment $1570 \mathrm{~A}$ formed at the desired run temperature and not during the cooling from 1050 to $850{ }^{\circ} \mathrm{C}$.

The normalised garnets display $0.03-0.05$ cations per formula unit (pfu) of HREE+Y and Si of 2.98-2.94 pfu, respectively (Table 4). This suggests that incorporation of trivalent cations for divalent $\mathrm{Mg}, \mathrm{Ca}$ or $\mathrm{Fe}$ is compensated by substitution of $\mathrm{Al}$ on the tetrahedral Si-site in a YAGtype substitution $\left(\mathrm{Y}_{3} \mathrm{Al}_{5} \mathrm{O}_{12}\right)$.

\subsubsection{Zircon}

Zircon (Table 5) is characterised by a steep pattern with low LREE and high HREE, due to the fact that the REEs with smaller ionic radius better fit the $\mathrm{Zr}$ site in which they substitute (e.g. Hinton and Upton, 1991; Hoskin and Schaltegger, 2003). As for natural zircon, $U$ is more readily incorporated than $\mathrm{Th}$, resulting in a $\mathrm{Th} / \mathrm{U}$ around $0.3-0.4$, which is significantly lower than the value of 0.89 in the starting material. There is a significant increase in $\mathrm{P}, \mathrm{Th}, \mathrm{U}$ and HREE with decreasing temperature. Within the error of the analyses, there is no variation in $\mathrm{Hf}$ contents with $T$. At 800 and $850{ }^{\circ} \mathrm{C}$ the Th and $\mathrm{U}$ contents of zircon are very high and reach percent levels. Electron microprobe analyses of zircon grains displayed a larger variation than the LA-ICP-MS values but confirmed the $\mathrm{P}$, $\mathrm{Y}, \mathrm{Yb}, \mathrm{U}$ and $\mathrm{Th}$ concentrations obtained by regression (Table 5). Such high levels of Th and U are likely related to the fact that the substitution of these elements for $\mathrm{Zr}^{4+}$ does not require any coupled incorporation of another trace element for charge balance. In contrast, incorporation of $\mathrm{Y}$ and REE requires coupled substitutions. It has been shown that phosphorus plays a major role for such a charge balance (e.g. Speer, 1982; Hoskin, 2000; Hanchar et al., 2001). In fact, a reconnaissance experiment at 
Table 4

Major (in wt. $\% \pm 1 \sigma$ S.D.) and trace (in ppm $\pm 1 \sigma$ S.D.) element composition of garnet

\begin{tabular}{|c|c|c|c|c|c|c|c|c|c|c|}
\hline Run N. & \multicolumn{2}{|l|}{$1587 \mathrm{~A}$} & \multicolumn{2}{|l|}{$1570 \mathrm{~A}$} & \multicolumn{2}{|l|}{$1640 \mathrm{~A}$} & \multicolumn{2}{|l|}{$1583 \mathrm{~A}$} & \multicolumn{2}{|l|}{2380} \\
\hline $\mathrm{T}-\mathrm{P}$ & \multicolumn{2}{|c|}{$800^{\mathrm{a}}-20$} & \multicolumn{2}{|c|}{$850^{\mathrm{a}}-20$} & \multicolumn{2}{|c|}{$900^{\mathrm{a}}-20$} & \multicolumn{2}{|c|}{$950^{\mathrm{a}}-20$} & \multicolumn{2}{|c|}{$1000^{\mathrm{a}}-20$} \\
\hline \multirow[t]{2}{*}{ No. of analysis } & \multicolumn{2}{|c|}{9} & \multicolumn{2}{|c|}{7} & \multicolumn{2}{|c|}{11} & \multicolumn{2}{|c|}{8} & \multicolumn{2}{|c|}{46} \\
\hline & wt.\% & $\pm 1 \sigma$ & wt. $\%$ & $\pm 1 \sigma$ & wt. $\%$ & $\pm 1 \sigma$ & wt.\% & $\pm 1 \sigma$ & wt. $\%$ & $\pm 1 \sigma$ \\
\hline $\mathrm{SiO}_{2}$ & 37.63 & 0.36 & 37.77 & 0.58 & 38.43 & 0.33 & 38.81 & 0.53 & 39.86 & 0.27 \\
\hline $\mathrm{Al}_{2} \mathrm{O}_{3}$ & 21.48 & 0.15 & 21.33 & 0.20 & 22.05 & 0.33 & 21.83 & 0.18 & 23.06 & 0.13 \\
\hline $\mathrm{FeO}$ & 24.63 & 0.48 & 23.51 & 0.46 & 24.24 & 0.80 & 24.07 & 0.42 & 22.66 & 0.42 \\
\hline $\mathrm{MgO}$ & 6.49 & 0.10 & 8.47 & 0.30 & 9.83 & 0.54 & 10.87 & 0.27 & 11.67 & 0.30 \\
\hline $\mathrm{CaO}$ & 7.86 & 0.39 & 6.01 & 0.38 & 4.02 & 0.30 & 3.19 & 0.35 & 3.05 & 0.12 \\
\hline$\left(\mathrm{M}^{3+}\right)_{2} \mathrm{O}_{3}$ & 1.91 & & 1.42 & & 0.92 & & 1.17 & & 1.02 & \\
\hline Total & 100.00 & & 98.51 & & 99.49 & & 99.93 & & 101.31 & \\
\hline $\mathrm{Mg} \#^{\mathrm{b}}$ & 0.33 & & 0.40 & & 0.43 & & 0.46 & & 0.49 & \\
\hline Cations on the $b$ & & & & & & & & & & \\
\hline $\mathrm{Si}$ & 2.94 & & 2.96 & & 2.96 & & 2.97 & & 2.98 & \\
\hline $\mathrm{Al}$ & 1.98 & & 1.97 & & 2.00 & & 1.96 & & 2.03 & \\
\hline $\mathrm{Fe}^{3+}$ & 0.08 & & 0.08 & & 0.06 & & 0.07 & & 0.04 & \\
\hline $\mathrm{Fe}^{2+}$ & 1.53 & & 1.46 & & 1.50 & & 1.47 & & 1.38 & \\
\hline $\mathrm{Mg}$ & 0.76 & & 0.99 & & 1.13 & & 1.24 & & 1.30 & \\
\hline $\mathrm{Ca}$ & 0.66 & & 0.50 & & 0.33 & & 0.26 & & 0.24 & \\
\hline $\mathrm{Y}+\mathrm{HREE}$ & 0.05 & & 0.04 & & 0.03 & & 0.03 & & 0.03 & \\
\hline
\end{tabular}

\begin{tabular}{|c|c|c|c|c|c|c|c|c|c|c|}
\hline No. of analysis & 4 & & 6 & & 3 & & 6 & & 5 & \\
\hline & ppm & $\pm 1 \sigma$ & ppm & $\pm 1 \sigma$ & ppm & $\pm 1 \sigma$ & ppm & $\pm 1 \sigma$ & ppm & $\pm 1 \sigma$ \\
\hline $\mathrm{P}$ & 1619 & 133 & 987 & 82 & 610 & 49 & 388 & 50 & 913 & 128 \\
\hline $\mathrm{Y}$ & 2683 & 328 & 2348 & 432 & 1683 & 449 & 2073 & 260 & 1890 & 200 \\
\hline $\mathrm{Zr}$ & 200 & 10 & 257 & 21 & 205 & 14 & 349 & 46 & 814 & 72 \\
\hline $\mathrm{Ba}$ & $<0.02$ & & $<0.02$ & & $<0.02$ & & $<0.02$ & & 0.99 & \\
\hline $\mathrm{La}$ & 0.12 & 0.05 & 0.29 & 0.07 & 0.22 & 0.08 & 0.19 & 0.03 & 0.40 & 0.21 \\
\hline $\mathrm{Ce}$ & 0.5 & 0.1 & 1.9 & 0.4 & 1.9 & 0.6 & 1.8 & 0.3 & 2.5 & 0.7 \\
\hline $\operatorname{Pr}$ & 1.8 & 0.2 & 8.6 & 1.2 & 11 & 3 & 9.7 & 1.5 & 14 & 4 \\
\hline $\mathrm{Nd}$ & 6 & 1 & 33 & 4 & 44 & 13 & 42 & 7 & 53 & 12 \\
\hline $\mathrm{Sm}$ & 44 & 2 & 232 & 14 & 338 & 81 & 327 & 47 & 355 & 52 \\
\hline $\mathrm{Eu}$ & 153 & 9 & 398 & 24 & 362 & 81 & 375 & 56 & 344 & 42 \\
\hline $\mathrm{Gd}$ & 232 & 16 & 693 & 25 & 880 & 118 & 985 & 111 & 968 & 101 \\
\hline Dy & 1215 & 121 & 1589 & 215 & 1441 & 298 & 1777 & 179 & 1693 & 173 \\
\hline $\mathrm{Er}$ & 2962 & 361 & 2357 & 533 & 1594 & 576 & 2028 & 313 & 1731 & 214 \\
\hline $\mathrm{Yb}$ & 4783 & 660 & 2980 & 803 & 1638 & 672 & 2143 & 421 & 1772 & 231 \\
\hline $\mathrm{Lu}$ & 4825 & 745 & 2909 & 800 & 1526 & 658 & 1989 & 421 & 1596 & 216 \\
\hline Hf & 13 & 1 & 15 & 1 & 10 & 1 & 19 & 4 & 43 & 4 \\
\hline Th & 2.6 & 0.2 & 4.2 & 0.9 & 0.81 & 0.41 & 0.82 & 0.31 & 2.6 & 1.5 \\
\hline $\mathrm{U}$ & 84 & 11 & 59 & 8 & 11 & 4 & 11 & 3 & 18 & 7 \\
\hline
\end{tabular}

${ }^{\text {a }}$ With initial $2 \mathrm{~h}$ heating step at $1050{ }^{\circ} \mathrm{C}$.

b $\mathrm{Mg} /\left(\mathrm{Mg}+\mathrm{Fe}^{2+}\right)$.

$900{ }^{\circ} \mathrm{C}(1245)$ was performed with a different starting material containing low phosphorus contents of only about $70 \mathrm{ppm}$. As a result $Y$ and the HREE in zircon are about five times lower than in an experiment at the same temperature that contained $500 \mathrm{ppm}$ phosphorus. We also performed an experiment with much higher phosphorous contents where zircon coexisted with apatite and monazite. However, in this experiment it was impossible to determine the zircon composition with LA-ICP-MS because of the inevitable presence of small trace element rich phases such as apatite and monazite.

\section{Trace element partitioning}

\subsection{Garnet/melt}

Garnet/melt distribution coefficients $\left(D^{\text {Grt/Melt }}\right)$ were calculated for the experiments between 800 and $1000{ }^{\circ} \mathrm{C}$ using the compositions given in Tables 3 and 4. The data (Table 6, Fig. 6a) indicate that the LREE partition preferentially into the melt, whereas the HREE are enriched in the garnet. The Th and $U$ are incompatible in garnet whereas $\mathrm{Zr}$ and $\mathrm{Hf}$ partition coefficients are close 
to unity. Our extended data set allows consideration of the temperature effect on partitioning in a constant bulk composition. There is a systematic decrease in partition coefficient for nearly all trace elements with increasing temperature. This trend, already identified by Nicholls and Harris (1980) for Sm, Dy and Yb, is clearly visible in the HFSE and the LREE and less pronounced in the HREE (Fig. 6a). Exceptions to this trend are the HREE in experiments 1640A@900 ${ }^{\circ} \mathrm{C}$ and 2380@1000 ${ }^{\circ} \mathrm{C}$, which are slightly steeper than the patterns from other experiments.

The general pattern of garnet-melt REE distribution coefficients is in agreement with that reported by previous workers (Sisson and Bacon, 1992; Van Westrenen et al., 1999; Van Westrenen et al., 2001), although comparison with literature data is complicated by differences in garnet
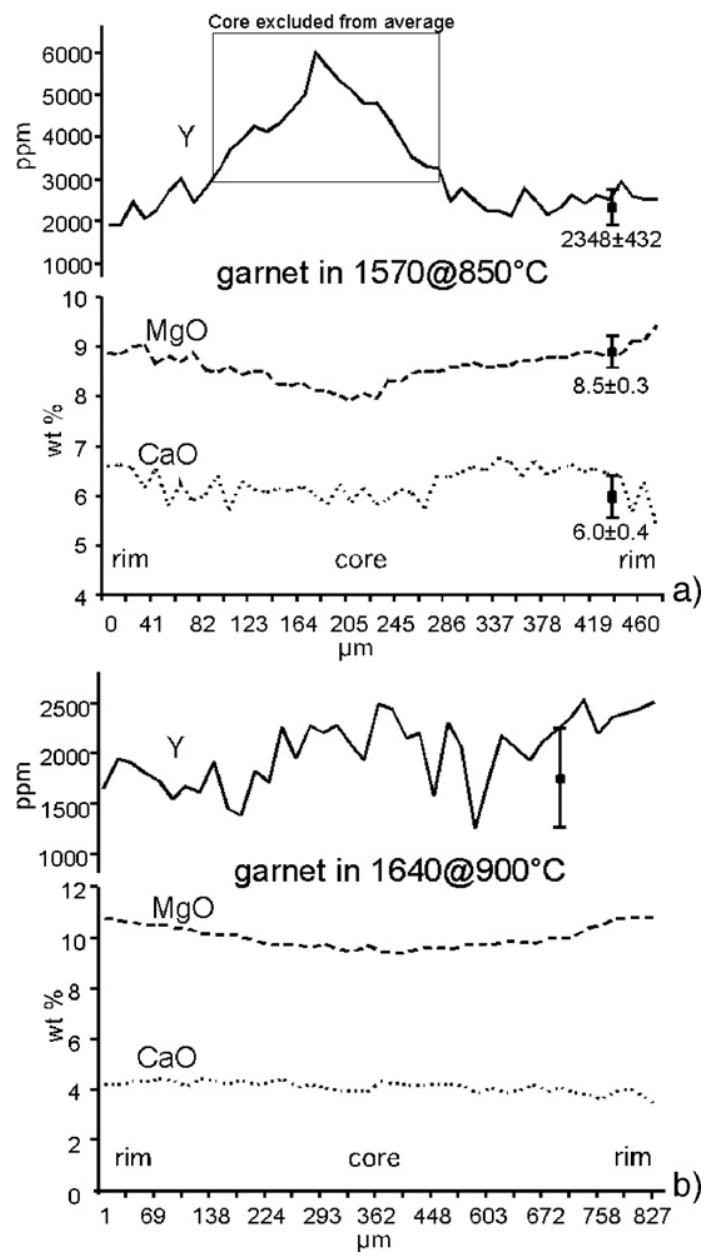

Fig. 5. Compositional profiles measured by electron microprobe across garnet. Filled squares represent the average concentration of $\mathrm{Y}, \mathrm{MgO}$ and $\mathrm{CaO}$ measured by LA-ICP-MS (for Y; analysis of garnet rim) or $\mathrm{EDS}$ (for $\mathrm{MgO}$ and $\mathrm{CaO}$ ) with $1 \sigma$ error bar. and melt composition, pressure and temperature (Fig. 6b). The values from Sisson and Bacon (1992) refer to a garnet phenocryst in a high-silica rhyolite, and were analysed using an ion microprobe. The obtained REE pattern is steeper than what is generally observed from experimentally determined garnet/melt partitioning data sets. Additionally, the partitioning of HREE proposed by Sisson and Bacon (1992), equilibrated at $980{ }^{\circ} \mathrm{C}$, is significantly higher than what we observe in the $800{ }^{\circ} \mathrm{C}$ experiment, which has the greatest enrichment of HREE in garnet. The partitioning data produced experimentally by Nicholls and Harris (1980) for garnet in equilibrium with andesitic liquid at $960^{\circ} \mathrm{C}$ and $20 \mathrm{kbar}$ is similar to our data. A more recent experimental study on garnet/melt partitioning by Van Westrenen et al. (1999) on pyroperich garnet $\left(\mathrm{Py}_{60}\right)$ at $1530{ }^{\circ} \mathrm{C}$ produced HREE values that are in line with our temperature trend. In this case, however, the difference in garnet composition $\left(\mathrm{Py}_{60}\right.$ versus our $\mathrm{Py}_{25-46}$ ) might be too big for meaningful comparison.

The distribution coefficient obtained can be fitted into the crystal-melt partitioning model of Blundy and Wood (1994). This model is based on the observation that mineral/melt partition coefficients for isovalent cations show a near-parabolic dependence on cation radius (Onuma et al., 1968). Blundy and Wood (1994) used the lattice strain model of Brice (1975) to define the equation

$D_{\mathrm{i}}=D_{0} \times \exp \left\{\frac{-4 \pi E N_{\mathrm{A}}\left[\frac{r_{0}}{2}\left(r_{\mathrm{i}}-r_{0}\right)^{2}+\frac{1}{3}\left(r_{\mathrm{i}}-r_{0}\right)^{3}\right]}{R T}\right\}$

where the trace element partition of a given structural site $\left(D_{\mathrm{i}}\right)$ is characterised by the site ionic radius $\left(r_{0}\right.$, in $\left.\AA\right)$, its Young's modulus ( $E$, in $\mathrm{GPa})$ and the theoretical partition coefficient $\left(D_{0}\right)$ for an element with ideal radius $r_{0}$. In Eq. (1), $N_{\mathrm{A}}$ is Avogadro's number, $R$ is the gas constant and $T$ is in $\mathrm{K}$.

The REE data of Table 4 were fitted to the lattice strain model of Blundy and Wood (1994) defined by Eq. (1). Van Westrenen et al. (1999, 2000, 2001) demonstrated that this model could be successfully applied to garnet-melt partitioning of REE. The data were fitted using the eight-fold coordinated ionic radii of Shannon (1976), and weighted using the one sigma value reported in Table 4. The Onuma diagrams obtained show a good fit of our experimental data to the Blundy and Wood (1994) model (an example is reported in Fig. 6c, the complete series of diagrams is available in the background data set). The measured distribution coefficient for $\mathrm{Eu}$ is generally lower than the model 
Table 5

Trace element composition of zircon in $\mathrm{ppm} \pm 1 \sigma$

\begin{tabular}{|c|c|c|c|c|c|c|c|c|c|c|c|c|}
\hline \multirow{2}{*}{$\frac{\text { Run no. }}{T-P}$} & \multicolumn{2}{|l|}{$1743-$ calc $^{\mathrm{a}}$} & \multicolumn{2}{|l|}{$1690 \mathrm{~A}-\mathrm{calc}^{\mathrm{a}}$} & \multicolumn{2}{|l|}{$1640 \mathrm{~A}-$ calc $^{\mathrm{a}}$} & \multicolumn{2}{|l|}{$1583 \mathrm{~A}-$ calc $^{\mathrm{a}}$} & \multicolumn{2}{|l|}{$1589 \mathrm{~A}-\mathrm{calc}^{\mathrm{a}}$} & \multicolumn{2}{|l|}{$1605 \mathrm{~A}-\mathrm{calc}^{\mathrm{a}}$} \\
\hline & \multicolumn{2}{|l|}{$800-20$} & \multicolumn{2}{|l|}{$850-20$} & \multicolumn{2}{|l|}{$900^{b}-20$} & \multicolumn{2}{|l|}{$950^{\mathrm{b}}-20$} & \multicolumn{2}{|l|}{$1000-20$} & \multicolumn{2}{|l|}{$1050-20$} \\
\hline $\begin{array}{l}\text { No. of } \\
\text { analysis }\end{array}$ & 12 & $\mathrm{LCC}$ & 14 & $\mathrm{LCC}$ & 8 & LCC & 6 & $\mathrm{LCC}$ & 7 & $\mathrm{LCC}$ & 6 & LCC \\
\hline $\mathrm{P}$ & $8313 \pm 1389$ & 0.87 & & - & $2742 \pm 663$ & 0.77 & - & & - & & $2379 \pm 514$ & 0.84 \\
\hline P EMP & & & & & $3770 \pm 1687$ & & & & & & & \\
\hline $\mathrm{Y}$ & $5373 \pm 150$ & 1.00 & $5561 \pm 136$ & 1.00 & $3081 \pm 39$ & 1.00 & $2537 \pm 199$ & 1.00 & $2305 \pm 82$ & 1.00 & $2360 \pm 46$ & 1.00 \\
\hline Y EMP & & & $3349 \pm 833$ & & $2629 \pm 1306$ & & & & & & & \\
\hline $\mathrm{Zr}$ & $410,000 \pm 10,000$ & & $41,5000 \pm 10,000$ & & $44,5000 \pm 10,000$ & & $44,5000 \pm 10,000$ & & $45,0000 \pm 10,000$ & & $45,0000 \pm 10,000$ & - \\
\hline $\mathrm{Nd}$ & $382 \pm 58$ & 0.89 & - & & - & & - & & & & $451 \pm 29$ & 0.93 \\
\hline $\mathrm{Sm}$ & $1071 \pm 118$ & 0.94 & $644 \pm 81$ & 0.91 & $358 \pm 37$ & 0.79 & - & & $511 \pm 49$ & 0.88 & $591 \pm 60$ & 0.93 \\
\hline $\mathrm{Eu}$ & $912 \pm 33$ & 0.99 & $623 \pm 97$ & 0.85 & - & & - & & - & & $450 \pm 46$ & 0.87 \\
\hline $\mathrm{Gd}$ & $1906 \pm 38$ & 1.00 & $1876 \pm 58$ & 0.99 & $870 \pm 35$ & 0.99 & $963 \pm 170$ & 0.84 & $896 \pm 66$ & 0.98 & $885 \pm 39$ & 0.99 \\
\hline Dy & $3760 \pm 90$ & 1.00 & $3856 \pm 149$ & 0.99 & $1918 \pm 33$ & 1.00 & $1670 \pm 259$ & 0.98 & $1531 \pm 56$ & 1.00 & $1603 \pm 56$ & 1.00 \\
\hline $\mathrm{Er}$ & $5463 \pm 145$ & 1.00 & $5508 \pm 245$ & 0.99 & $3299 \pm 47$ & 1.00 & $2894 \pm 228$ & 1.00 & $2494 \pm 131$ & 0.99 & $2680 \pm 68$ & 1.00 \\
\hline $\mathrm{Yb}$ & $7579 \pm 217$ & 1.00 & $7711 \pm 344$ & 0.99 & $4721 \pm 53$ & 1.00 & $4412 \pm 596$ & 0.97 & $3767 \pm 79$ & 1.00 & $4046 \pm 56$ & 1.00 \\
\hline Yb EMP & $5165 \pm 846$ & & $6661 \pm 659$ & & $5803 \pm 1819$ & & & & & & & \\
\hline $\mathrm{Lu}$ & $8712 \pm 245$ & 1.00 & $8070 \pm 305$ & 0.99 & $5412 \pm 85$ & 1.00 & $4764 \pm 499$ & 0.98 & $4124 \pm 125$ & 1.00 & $4634 \pm 74$ & 1.00 \\
\hline $\mathrm{Hf}$ & $29,606 \pm 456$ & 1.00 & $26,259 \pm 1535$ & 0.98 & $26,099 \pm 568$ & 1.00 & $29,784 \pm 950$ & 1.00 & $28,273 \pm 659$ & 1.00 & $28,104 \pm 347$ & 1.00 \\
\hline $\mathrm{Th}$ & $6157 \pm 287$ & 0.99 & $4950 \pm 268$ & 0.98 & $2762 \pm 87$ & 1.00 & $2667 \pm 526$ & 0.92 & $1878 \pm 86$ & 0.99 & $1998 \pm 94$ & 0.99 \\
\hline Th EMP & $4318 \pm 935$ & & $3593 \pm 935$ & & $2664 \pm 1191$ & & & & & & & \\
\hline $\mathrm{U}$ & $18,321 \pm 702$ & 0.99 & $18,454 \pm 1261$ & 0.97 & $7408 \pm 205$ & 1.00 & $7638 \pm 549$ & 0.99 & $6031 \pm 144$ & 1.00 & $5654 \pm 206$ & 1.00 \\
\hline U EMP & $15,944 \pm 2188$ & & $16,967 \pm 1364$ & & $9570 \pm 2245$ & & & & & & & \\
\hline $\mathrm{Hf} / \mathrm{Zr}$ & $0.072 \pm 0.003$ & & $0.063 \pm 0.005$ & & $0.059 \pm 0.003$ & & $0.067 \pm 0.004$ & & $0.063 \pm 0.003$ & & $0.062 \pm 0.002$ & \\
\hline $\mathrm{Th} / \mathrm{U}$ & $0.34 \pm 0.03$ & & $0.27 \pm 0.03$ & & $0.37 \pm 0.02$ & & $0.35 \pm 0.09$ & & $0.31 \pm 0.02$ & & $0.35 \pm 0.03$ & \\
\hline
\end{tabular}

Values were calculated by regressing mixed zircon-melt analyses measured with LA-ICP-MS. EMP measurement of zircon for some elements (in italic) are given for comparison.

LCC $=$ linear correlation coefficient $(R)$.

$-=$ not given because of poor regression $(R<0.750)$.

EMP $=$ electron microprobe analysis

${ }^{a}$ Composition calculated using a linear regression between melt and zircon.

${ }^{\mathrm{b}}$ With initial $2 \mathrm{~h}$ heating step at $1050{ }^{\circ} \mathrm{C}$.

prediction, indicating that Eu was partly divalent in the experiments, as it is expected in natural rocks. The exclusion of the Eu data does not change the best-fit parameters significantly. The fitted $D_{0}$ value generally decreases with increasing temperature (Table 7), consistent with the model by Van Westrenen et al. (2001), and Wood and Blundy (2002). With the exclusion of the value from the $950{ }^{\circ} \mathrm{C}$ experiment, linear regression of $\ln D_{0}$ against $1 / T$ (in $\mathrm{K}$ ) gives

$\ln D_{0}=0.0840+3760 / T$

with a linear correlation coefficient $R$ of 0.805 . Van Westrenen et al. (1999) reported that large variations in garnet composition in a small temperature range led to a positive correlation between $D_{0}$ values and the pyrope component in garnet. Our data set covers a significant temperature interval and range in garnet composition, but the correlation between $D_{0}$ and pyrope content is negative. This would suggest that, for our data, the variation of $D_{0}$ is primarily a function of $T$, and that the garnet composition effect is secondary. The same conclusion on the importance of $T$ was reached by Van Westrenen et al. (2001), when discussing the predictive model for garnet-melt trace element partitioning.

\subsection{Zircon/melt}

Distribution coefficients values between zircon and melt are reported in Table 6 and plotted in Fig. 7a. They were calculated using the trace element compositions of Tables 3 and 5. Experiments 1743@800 ${ }^{\circ} \mathrm{C}$ and $1690 @ 850{ }^{\circ} \mathrm{C}$ were run without the initial heating step at $1050{ }^{\circ} \mathrm{C}$, to avoid the formation of zircon at $1050{ }^{\circ} \mathrm{C}$ that were not able to re-equilibrate at the low temperature of the experiment. This problem did not occur at higher $T$, where any zircon formed during the $2 \mathrm{~h}$ at $1050{ }^{\circ} \mathrm{C}$ re-equilibrated at the desired $T$ during the long run. The generally small grain size of zircon of $\sim 5 \mu \mathrm{m}$ in experiments above $850{ }^{\circ} \mathrm{C}$ favoured trace element equilibration with the melt.

The values obtained cover a large $T$ interval of $250{ }^{\circ} \mathrm{C}$ and, more importantly, extend into temperatures below $950{ }^{\circ} \mathrm{C}$, which are relevant for amphibolite-, 
Table 6

Experimentally determined distribution coefficients $( \pm 1 \sigma)$

\begin{tabular}{|c|c|c|c|c|c|c|}
\hline $\mathrm{T}\left({ }^{\circ} \mathrm{C}\right)$ & 800 & 850 & 900 & 950 & 1000 & 1050 \\
\hline Run & $1587 \mathrm{~A}$ & $1570 \mathrm{~A}$ & $1640 \mathrm{~A}$ & $1583 \mathrm{~A}$ & 2380 & \\
\hline Phases & Grt/Mlt & Grt/Mlt & Grt/Mlt & Grt/Mlt & Grt/Mlt & \\
\hline $\mathrm{P}$ & $2.8 \pm 0.4$ & $1.4 \pm 0.4$ & $0.64 \pm 0.11$ & $0.59 \pm 0.10$ & $0.73 \pm 0.17$ & - \\
\hline Y & $39 \pm 6$ & $21 \pm 4$ & $17 \pm 5$ & $8.4 \pm 1.2$ & $12 \pm 1$ & - \\
\hline $\mathrm{Zr}$ & $2.2 \pm 0.1$ & $1.9 \pm 0.2$ & $1.1 \pm 0.1$ & $1.1 \pm 0.2$ & $1.9 \pm 0.2$ & - \\
\hline $\mathrm{La}$ & $0.066 \pm 0.037$ & $0.009 \pm 0.003$ & $0.0008 \pm 0.0003$ & $0.0006 \pm 0.0001$ & $0.0011 \pm 0.006$ & - \\
\hline $\mathrm{Ce}$ & $0.31 \pm 0.08$ & $0.065 \pm 0.017$ & $0.0067 \pm 0.0020$ & $0.0053 \pm 0.0010$ & $0.0067 \pm 0.0020$ & - \\
\hline $\operatorname{Pr}$ & $1.23 \pm 0.19$ & $0.31 \pm 0.05$ & $0.037 \pm 0.12$ & $0.030 \pm 0.005$ & $0.038 \pm 0.011$ & - \\
\hline $\mathrm{Nd}$ & $4.5 \pm 0.7$ & $1.1 \pm 0.2$ & $0.16 \pm 0.05$ & $0.13 \pm 0.02$ & $0.14 \pm 0.03$ & - \\
\hline Sm & $15 \pm 1$ & $5.8 \pm 0.6$ & $1.4 \pm 0.4$ & $1.1 \pm 0.2$ & $1.1 \pm 0.2$ & - \\
\hline $\mathrm{Eu}$ & $9.8 \pm 1.5$ & $5.2 \pm 0.5$ & $1.5 \pm 0.4$ & $1.3 \pm 0.2$ & $1.1 \pm 0.1$ & - \\
\hline $\mathrm{Gd}$ & $29 \pm 4$ & $14 \pm 1$ & $5.3 \pm 0.9$ & $3.7 \pm 0.5$ & $3.9 \pm 0.4$ & - \\
\hline Dy & $36 \pm 5$ & $20 \pm 3$ & $13 \pm 3$ & $7.3 \pm 0.9$ & $9.5 \pm 1.1$ & - \\
\hline $\mathrm{Er}$ & $40 \pm 6$ & $22 \pm 5$ & $22 \pm 8$ & $9.3 \pm 1.5$ & $14 \pm 2$ & - \\
\hline $\mathrm{Yb}$ & $43 \pm 7$ & $22 \pm 6$ & $27 \pm 12$ & $10.0 \pm 2.2$ & $18 \pm 2$ & - \\
\hline $\mathrm{Lu}$ & $40 \pm 7$ & $21 \pm 6$ & $28 \pm 13$ & $9.7 \pm 2.2$ & $18 \pm 3$ & - \\
\hline $\mathrm{Hf}$ & $1.3 \pm 0.2$ & $1.1 \pm 0.1$ & $0.70 \pm 0.08$ & $0.71 \pm 0.15$ & $1.3 \pm 0.2$ & - \\
\hline Th & $0.34 \pm 0.11$ & $0.074 \pm 0.017$ & $0.0028 \pm 0.0014$ & $0.0026 \pm 0.0010$ & $0.0073 \pm 0.0042$ & - \\
\hline $\mathrm{U}$ & $0.85 \pm 0.14$ & $0.31 \pm 0.05$ & $0.036 \pm 0.013$ & $0.033 \pm 0.010$ & $0.052 \pm 0.020$ & - \\
\hline Run & 1743 & $1690 \mathrm{~A}$ & $1640 \mathrm{~A}$ & $1583 \mathrm{~A}$ & 1589 & $1605 \mathrm{~A}$ \\
\hline Phases & Zrn/Mlt & $\mathrm{Zrn} / \mathrm{Mlt}$ & Zrn/Mlt & $\mathrm{Zrn} / \mathrm{Mlt}$ & $\mathrm{Zrn} / \mathrm{Mlt}$ & $\mathrm{Zrn} / \mathrm{Mlt}$ \\
\hline$P$ & $10 \pm 3$ & - & $2.9 \pm 1.0$ & - & - & $2.5 \pm 0.6$ \\
\hline $\mathrm{Y}$ & $149 \pm 9$ & $121 \pm 11$ & $30 \pm 1$ & $10 \pm 1$ & $8.7 \pm 0.4$ & $7.8 \pm 0.3$ \\
\hline $\mathrm{Zr}$ & $2005 \pm 248$ & $3120 \pm 216$ & $2497 \pm 119$ & $1353 \pm 55$ & $795 \pm 24$ & $535 \pm 18$ \\
\hline $\mathrm{La}$ & - & - & - & - & - & - \\
\hline $\mathrm{Ce}$ & - & - & - & - & - & - \\
\hline $\operatorname{Pr}$ & - & - & - & - & - & - \\
\hline $\mathrm{Nd}$ & $8.5 \pm 1.8$ & - & & - & - & $1.5 \pm 0.1$ \\
\hline Sm & $16 \pm 3$ & $12 \pm 2$ & $1.5 \pm 0.2$ & - & $1.6 \pm 0.2$ & $2.0 \pm 0.2$ \\
\hline $\mathrm{Eu}$ & $8.5 \pm 0.7$ & $6.7 \pm 1.2$ & - & - & - & $1.5 \pm 0.2$ \\
\hline Gd & $30 \pm 1$ & $32 \pm 2$ & $5.3 \pm 0.4$ & $3.6 \pm 0.7$ & $3.1 \pm 0.3$ & $3.1 \pm 0.2$ \\
\hline Dy & $100 \pm 6$ & $75 \pm 8$ & $18 \pm 1$ & $6.9 \pm 1.2$ & $5.8 \pm 0.3$ & $5.6 \pm 0.3$ \\
\hline $\mathrm{Er}$ & $214 \pm 18$ & $153 \pm 31$ & $45 \pm 2$ & $13 \pm 1$ & $12 \pm 1$ & $10 \pm 0.4$ \\
\hline $\mathrm{Yb}$ & $345 \pm 41$ & $226 \pm 64$ & $78 \pm 3$ & $20 \pm 3$ & $20 \pm 1$ & $15 \pm 0.4$ \\
\hline $\mathrm{Lu}$ & $445 \pm 42$ & $274 \pm 78$ & $98 \pm 4$ & $23 \pm 3$ & $26 \pm 2$ & $18 \pm 1$ \\
\hline $\mathrm{Hf}$ & $3476 \pm 476$ & - & $1829 \pm 122$ & $1100 \pm 61$ & $698 \pm 27$ & $492 \pm 15$ \\
\hline $\mathrm{Th}$ & $41 \pm 4$ & $45 \pm 5$ & $9.4 \pm 0.5$ & $8.4 \pm 1.8$ & $5.7 \pm 0.3$ & $6.1 \pm 0.4$ \\
\hline $\mathrm{U}$ & $167 \pm 17$ & $157 \pm 51$ & $24 \pm 1$ & $23 \pm 2$ & $18 \pm 1$ & $15 \pm 1$ \\
\hline Run & $1743 / 1587$ & $1690 \mathrm{~A} / 1570 \mathrm{~A}$ & $1640 \mathrm{~A}$ & $1583 \mathrm{~A}$ & $1589 / 2380$ & \\
\hline Phases & $\mathrm{Zrn} / \mathrm{Grt}$ & $\mathrm{Zrn} / \mathrm{Grt}$ & $\mathrm{Zrn} / \mathrm{Grt}$ & $\mathrm{Zrn} / \mathrm{Grt}$ & $\mathrm{Zrn} / \mathrm{Grt}$ & \\
\hline $\bar{P}$ & $3.6 \pm 1.4$ & - & $4.5 \pm 1.5$ & - & - & - \\
\hline Y & $3.8 \pm 0.8$ & $5.8 \pm 1.7$ & $1.8 \pm 0.6$ & $1.2 \pm 0.3$ & $0.74 \pm 0.13$ & - \\
\hline $\mathrm{Zr}$ & $2308 \pm 261$ & $1614 \pm 319$ & $2174 \pm 154$ & $1276 \pm 171$ & $418 \pm 46$ & - \\
\hline $\mathrm{La}$ & - & - & - & - & - & - \\
\hline $\mathrm{Ce}$ & - & - & - & - & - & - \\
\hline $\operatorname{Pr}$ & - & - & - & - & - & - \\
\hline $\mathrm{Nd}$ & $1.9 \pm 0.7$ & - & - & - & - & - \\
\hline $\mathrm{Sm}$ & $1.1 \pm 0.3$ & $2.0 \pm 0.5$ & $1.1 \pm 0.4$ & - & $1.5 \pm 0.4$ & - \\
\hline $\mathrm{Eu}$ & $0.87 \pm 0.21$ & $1.3 \pm 0.4$ & - & - & - & - \\
\hline $\mathrm{Gd}$ & $1.0 \pm 0.2$ & $2.3 \pm 0.3$ & $0.99 \pm 0.18$ & $1.0 \pm 0.3$ & $0.81 \pm 0.17$ & - \\
\hline Dy & $2.8 \pm 0.5$ & $3.8 \pm 0.9$ & $1.3 \pm 0.3$ & $0.9 \pm 0.2$ & $0.60 \pm 0.10$ & - \\
\hline $\mathrm{Er}$ & $5.4 \pm 1.3$ & $6.9 \pm 3.1$ & $2.1 \pm 0.9$ & $1.4 \pm 0.3$ & $0.80 \pm 0.18$ & - \\
\hline $\mathrm{Yb}$ & $8.0 \pm 2.3$ & $10 \pm 6$ & $2.9 \pm 1.5$ & $2.1 \pm 0.7$ & $1.2 \pm 0.2$ & - \\
\hline $\mathrm{Lu}$ & $11 \pm 3$ & $13 \pm 8$ & $3.5 \pm 1.9$ & $2.4 \pm 0.8$ & $1.4 \pm 0.3$ & - \\
\hline $\mathrm{Hf}$ & $2761 \pm 742$ & - & $2625 \pm 245$ & $1546 \pm 365$ & $522 \pm 82$ & - \\
\hline Th & $119 \pm 53$ & $605 \pm 12$ & $3391 \pm 2384$ & $3251 \pm 2177$ & $778 \pm 728$ & - \\
\hline $\mathrm{U}$ & $196 \pm 53$ & $514 \pm 248$ & $669 \pm 263$ & $706 \pm 277$ & $341 \pm 167$ & - \\
\hline
\end{tabular}

$-=$ not measured.

Errors on $D$ values are conservative estimates taking into account the errors on garnet, melt and zircon analyses and using the equation below where $C$ is the concentration of a given trace element in phases a and $\mathrm{b}$, and $\sigma$ is the error on that concentration. $\frac{\left(C_{x}+\sigma_{\alpha}\right)}{\left(C_{b}-\sigma_{b}\right)}+\frac{\left(C_{x}-\sigma_{\alpha}\right)}{\left(C_{b}+\sigma_{b}\right)}$ 

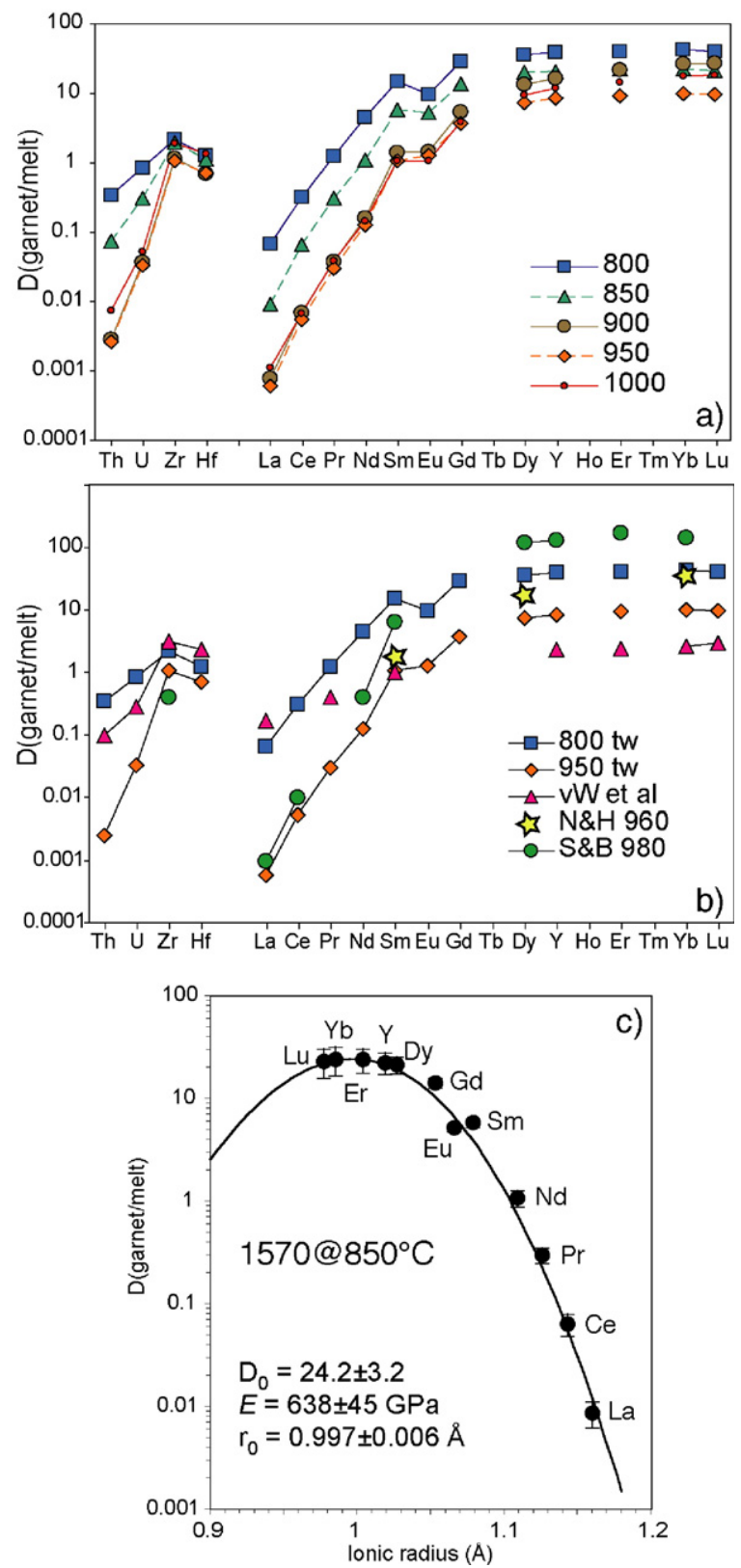

Fig. 6. Trace element distribution coefficients between garnet and melt. a) Own data for different temperatures. Errors are not plotted. b) Own data compared to literature data. Sources: tw: this work, $\mathrm{vW}$ et al.: experiment by Van Westrenen et al. (1999), N\&H 960: experiment by Nicholls and Harris (1980) at $960{ }^{\circ} \mathrm{C}, \mathrm{S} \& \mathrm{~B}$ 980: rhyolite equilibrated at $980{ }^{\circ} \mathrm{C}$ as measured by Sisson and Bacon (1992). See Section 5.1. for discussion. c) Onuma diagram for garnet/melt distribution coefficients of trivalent ions obtained from our experiment at $850{ }^{\circ} \mathrm{C}$. Data are fitted to the model of Blundy and Wood (1994), which uses the lattice strain model of Brice (1975). Eight coordinated ionic radii from Shannon (1976) are used. Data from Table 6. granulite-, and eclogite-facies metamorphism. The results in Table 6 represent the first set of experimentally determined partitioning for zircon/melt since Watson (1980), who limited his study to a few REE (La, Sm, Ho and $\mathrm{Lu}$ ). The method employed (see Section 2.3.) permits only the determination of trace element partitioning that is in favour of zircon, i.e. Th, U, Zr, Hf, MREE and HREE (Table 6, Fig. 7a). The zircon/melt distribution coefficient increases from MREE to HREE, as is expected from the decrease in ionic radius of the REE with increasing atomic number, approaching the ionic radius of $\mathrm{Zr}$.

Our data document that, for all the elements investigated, there is a decrease in partitioning values with increasing $T$ (Fig. 7a), a feature never documented before in zircon. For instance, the $D_{\mathrm{Lu}}^{\mathrm{Zrn} / \text { Melt }}$ decreases by a factor of 30 from 800 to $1050{ }^{\circ} \mathrm{C}$. The variation of the partitioning is generally linear in an Arrhenius plot with the exception of a few outliers (Fig. 7b). The small variation in major element composition of melt and zircon (Tables 3 and 5) indicates that the variation in $D^{\mathrm{Zrn} / \text { Melt }}$ seen in this study is mainly related to temperature rather than composition.

The unconstrained fitting of our data for trivalent cations to the Blundy and Wood (1994) model delivered unsatisfactory results. The parameters $D_{0}, E$ and $r_{0}$ defined by the fitted data between 800 and $950{ }^{\circ} \mathrm{C}$ have large errors, whereas for data at 1000 and $1050{ }^{\circ} \mathrm{C}$ the fit is not even realistic (Table 7). Excluding the MREE values, which are more difficult to determine accurately with our approach, improves the fit but the results are still not satisfactory. The problem of fitting zircon/melt data to the Blundy and Wood (1994) lattice strain model has been previously identified by Hanchar and Van Westrenen (personal comm.), who attribute it to the lack of data for elements smaller than Lu. An additional problem of the model is that it does not consider the simultaneous effect of substituting $\mathrm{P}$ for $\mathrm{Si}$ in zircon. Hanchar and Van Westrenen (personal comm.) developed an additional constraint on fitting literature zircon-melt REE partitioning data, by analysing the partitioning of fourteen REE between synthetic zircons and the $\mathrm{Li}-\mathrm{Mo}$ flux from which they were grown. Hanchar et al. (2001) synthesised fourteen zircons containing one REE each at constant experimental conditions. Calculated zircon-flux partition coefficients for all REE are fully consistent with the lattice strain model (Eq. (2)), and provide well-constrained best-fit parameters for $r_{0}, D_{0}$ and $E$. Hanchar and Van Westrenen (personal comm.) used the resulting values of $r_{0}$ and $E$ to derive an empirical equation linking $E$ with $r_{0}$. Such an equation was used successfully in the 
Table 7

Fitted parameters for zircon/melt partitioning to the lattice strain model

\begin{tabular}{|c|c|c|c|}
\hline $\mathrm{T}\left({ }^{\circ} \mathrm{C}\right)$ & $\mathrm{Do} \pm 1 \sigma$ & $\mathrm{E} \pm 1 \sigma$ & $\operatorname{ro} \pm 1 \sigma$ \\
\hline \multicolumn{4}{|c|}{ Zircon/melt. Unconstrained Blundy and Wood (1994) model } \\
\hline 800 & $1289 \pm 824$ & $315 \pm 93$ & $0.887 \pm 0.039$ \\
\hline 850 & $618 \pm 649$ & $288 \pm 149$ & $0.894 \pm 0.070$ \\
\hline 900 & $210 \pm 56$ & $444 \pm 69$ & $0.908 \pm 0.016$ \\
\hline 950 & $54 \pm 84$ & $230 \pm 252$ & $0.875 \pm 0.148$ \\
\hline $1000^{a}$ & $245 \pm 418$ & $138 \pm 79$ & $0.750 \pm 0.150$ \\
\hline $1050^{\mathrm{a}}$ & $422 \pm 786$ & $67 \pm 37$ & $0.570 \pm 0.250$ \\
\hline
\end{tabular}

Zircon/melt. Hanchar and Van Westrenen model

$\begin{array}{cccc}800 & 804 \pm 52 & 441 \pm 2 & 0.922 \pm 0.001 \\ 850 & 317 \pm 56 & 431 \pm 11 & 0.940 \pm 0.005 \\ 900 & 206 \pm 13 & 448 \pm 5 & 0.909 \pm 0.002 \\ 950 & 28 \pm 5 & 432 \pm 16 & 0.938 \pm 0.007 \\ 1000 & 31 \pm 3 & 437 \pm 7 & 0.928 \pm 0.003 \\ 1050 & 20 \pm 1 & 431 \pm 5 & 0.940 \pm 0.002\end{array}$

Garnet/melt. Unconstrained Blundy and Wood (1994) model

\begin{tabular}{cccc}
800 & $42.4 \pm 2.9$ & $499 \pm 39$ & $1.000 \pm 0.005$ \\
850 & $24.2 \pm 3.2$ & $638 \pm 45$ & $0.997 \pm 0.006$ \\
900 & $27.7 \pm 6.5$ & $647 \pm 98$ & $0.973 \pm 0.013$ \\
950 & $10.1 \pm 1.0$ & $845 \pm 44$ & $0.993 \pm 0.005$ \\
1000 & $21.9 \pm 3.0$ & $620 \pm 54$ & $0.958 \pm 0.008$ \\
\hline
\end{tabular}

${ }^{\mathrm{a}}$ Unrealistic fit.

past to model the relation between $r_{0}$ and $E$ for REE garnet-melt partitioning (Van Westrenen et al., 2000, 2001), and produces reasonable fits to literature zirconmelt REE partitioning data. The application of this constrained fit to our data (Fig. 8) is encouraging and argues for attainment of equilibrium between zircon and melt in the experiments. In the 800,1000 and $1050{ }^{\circ} \mathrm{C}$ series the elements with larger ionic radius ( $\mathrm{Sm}$ and $\mathrm{Nd}$ ) plot slightly off the trend. The low abundance of these elements in zircon and thus the poor estimate of their concentration with the employed analytical method is the likely cause of this offset.

The $D_{0}, E$ and $r_{0}$ parameters define with the constrained fit of Hanchar and Van Westrenen (personal comm.) are far more precise than what was obtained with the Blundy and Wood (1994) model (Table 7). The Young module $E$ is constant over the $T$ series (430$450 \mathrm{GPa}$ ), and the site ionic radius $r_{0}$ is close to the ionic radius of $\mathrm{Zr}(0.84 \AA)$ for which the REE substitute. Using the constrained fit the theoretical partition coefficient $D_{0}$ systematically decreases with increasing $T$ (Table 7), as expected for a consistent partitioning model (e.g. Green et al., 2000). This dependency of $D_{0}$ with temperature has never been shown before for zircon/melt partitioning. The $D_{0}$ value for the $950{ }^{\circ} \mathrm{C}$ fit is apparently too low and plots slightly off the trend defined by the other data. This is an indication that the fit to the $950{ }^{\circ} \mathrm{C}$ experimental distribution coefficients is poor and thus the $950{ }^{\circ} \mathrm{C}$ parameters should be used with caution. The linear regression of all $\ln D_{0}$ versus $1 / T$ (in K) gives:

$\ln D_{0}=-14.221+22420 / T \quad R=0.962$.

Using the parameters obtained with the constrained fit of Hanchar and Van Westrenen, $D^{\mathrm{Zrn} / \text { Melt }}$ for all the REE, including the LREE, which are missing in our experimental data set, can be calculated (Fig. 7c). Europium values should be considered as maximum values only, because in natural granitic systems zircon is characterised by a negative Eu anomaly (e.g. Heaman et al., 1990; Hinton and Upton, 1991). Similarly, the model $D_{\mathrm{Ce}}^{\mathrm{Zrn} / \text { Melt }}$ will be a minimum value because zircon in granitic rocks always has a positive Ce anomaly due to the presence of $\mathrm{Ce}^{+4}$ (Hinton and Upton, 1991; Hoskin and Schaltegger, 2003). The patterns show a kink at Sm with a steeper pattern for the LREE. The patterns at 800 and $900{ }^{\circ} \mathrm{C}$ are steeper than the other series resulting in lower LREE than what was suggested by the model values at $850,950,1000$ and $1050{ }^{\circ} \mathrm{C}$. Because the model is largely based on HREE data, the MREE and LREE model values are expected to be affected by large errors and this might explain some of the inconsistencies.

\subsection{Zircon/garnet}

Distribution coefficients between zircon and garnet $\left(D^{\mathrm{Zrn} / \mathrm{Grt}}\right)$ were calculated for five experiments between 800 and $1000{ }^{\circ} \mathrm{C}$. Two different methods were used. 1) Partitioning was calculated directly from the composition of garnet and zircon obtained from the same experiment (1640A@900 ${ }^{\circ} \mathrm{C}$ and 1583A@950 ${ }^{\circ} \mathrm{C}$ ). 2) At 800 850 and $1000{ }^{\circ} \mathrm{C}, D^{\mathrm{Zn} / \mathrm{Grt}}$ for each element $i$ was obtained by $D_{i}^{\mathrm{Zrn} / \mathrm{Grt}}=D_{i}^{\mathrm{Zrn} / \text { Melt }} / D_{i}^{\mathrm{Grt} / \text { Melt }}$, where $D_{i}^{\mathrm{Zrn} / \text { Melt }}$ and $D_{i}^{\mathrm{Gr} / \text { Melt }}$ were measured in two similar experiments run at the same $T$ in the same bulk composition, with or without the initial step at $1050{ }^{\circ} \mathrm{C}$. At these temperatures, zircon and garnet compositions could not be measured in the same experiment: the run with the initial heating step to $1050{ }^{\circ} \mathrm{C}$ produced the best garnet with limited zoning, but unsatisfactory zircon, whereas experiments without the heating step produced zircon that equilibrated with the melt but zoned garnet crystals. As we have shown above, the garnet rims in equilibrium with the melt have similar HREE concentrations in the two different experiments and therefore we are confident that this approach produces meaningful results, particularly for the $\mathrm{Y}$ and HREE, which are the main elements of interest for garnet-zircon partitioning. 

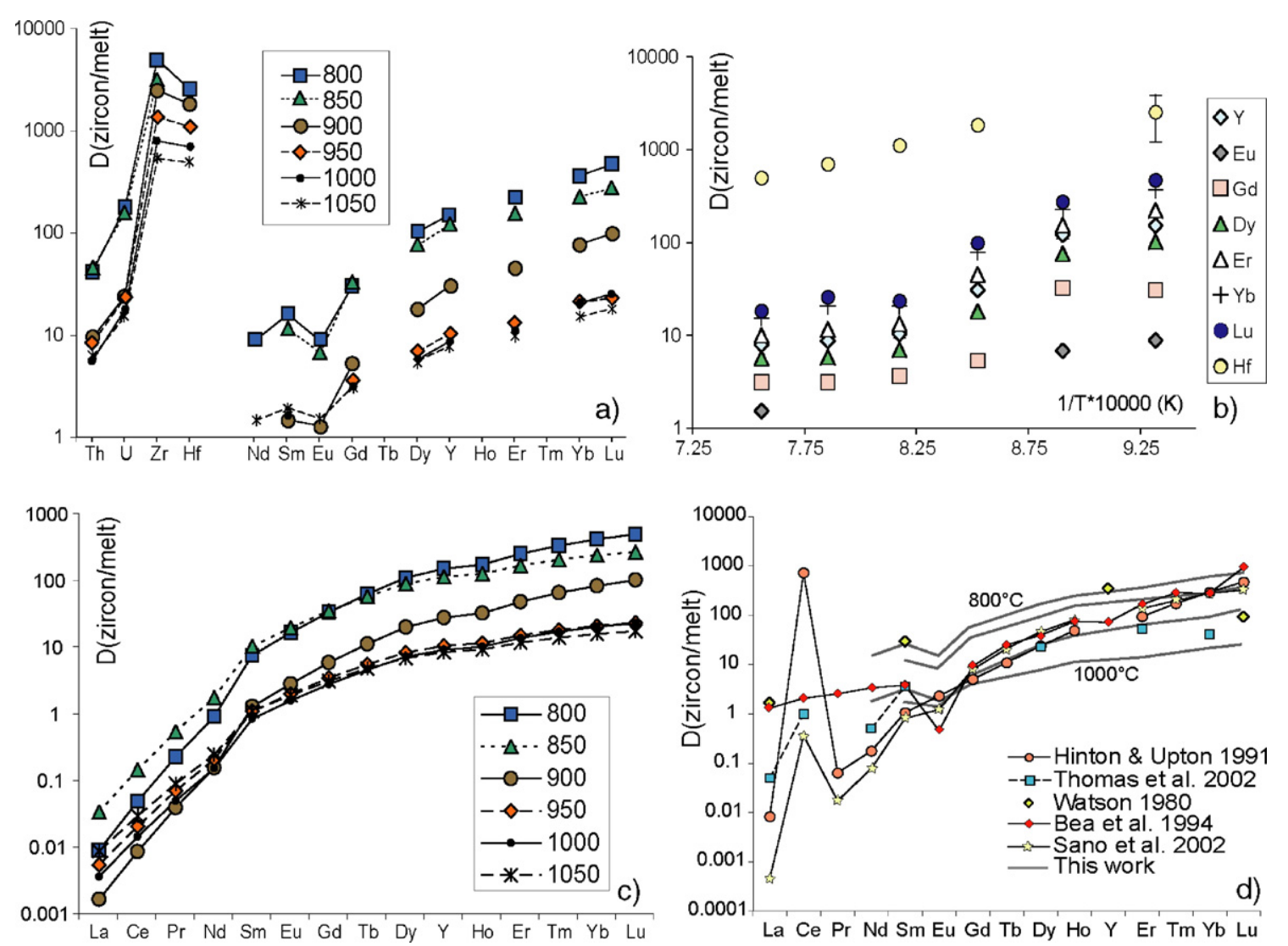

Fig. 7. Trace element distribution coefficients between zircon and melt: (a) Our experimental data from Table 6. (b) Variation of measured $D$ values for selected trace elements with temperature. Most errors are smaller than symbols. (c) Zircon/melt distribution coefficient values calculated using the lattice strain model of Hanchar and Van Westrenen (personal comm.), and fitted to the experimental data. d) Our zircon/melt partitioning data compared to some literature data. Only the data of Watson (1980) were experimentally determined. The other data are obtained by analysing zircon and melt (melt inclusions or whole rock) in natural rocks.

The $D^{\mathrm{Zrn} / \mathrm{Grt}}$ values were obtained for $\mathrm{P}, \mathrm{Y}, \mathrm{Zr}$, Nd to Lu, Hf, Th and U (Table 6, Fig. 9a). MREE equally partition between the two phases, whereas with increasing atomic number the HREE prefer zircon to garnet. As expected, $\mathrm{Zr}$, Hf, Th and $\mathrm{U}$ strongly partition into zircon. The $D_{\mathrm{REE}}^{Z \mathrm{rn} / \mathrm{Grt}}$ decreases with increasing temperature. Because of error propagation, some of the values presented have relatively large errors of $20-50 \%$ (Table 6 , see note in table for error calculation) and thus the series partly overlap (e.g. the 800 and $850{ }^{\circ} \mathrm{C} D_{\mathrm{HREE}}^{\mathrm{Zrn} / \mathrm{Grt}}$ ). However, there is a clear distinction between the experiments at the higher and the lower temperatures (Fig. 9a) indicating that there is a temperature trend for the HREE partitioning between garnet and zircon. For Th and $\mathrm{U}$ the large error on partitioning does not allow identifying a temperature trend. Even though values for the LREE could not be directly calculated, the patterns shown in Fig. 9a suggest that LREE are probably less depleted in zircon than in garnet, resulting in $D_{\mathrm{LREE}}^{\mathrm{Znn} / \mathrm{Grt}}$ above unity. This pattern agrees with measurements in natural samples, both eclogite- and granulite-facies rocks, where $D_{\mathrm{Nd}}^{\mathrm{Zrn} / \mathrm{Grt}}>D_{\mathrm{Gd}}^{\mathrm{Zrn} / \mathrm{Grt}}$ (Rubatto, 2002, see also Fig. 9b).

\section{Discussion}

\subsection{Approach to equilibrium}

The phases produced in all experiments display equilibrium textures (Fig. 1). Garnet formed in experiments with the initial heating step to $1050{ }^{\circ} \mathrm{C}$ displays nearly constant composition. Only a few large grains have a HREE enriched core (Fig. 5). The $\mathrm{Mg} / \mathrm{Fe}$ partitioning between garnet and melt changes systematically as a function of temperature (Tables 3, 4; Fig. 4a). Garnet has a lower $\mathrm{Mg} \#$ than the melt up to $950{ }^{\circ} \mathrm{C}$, at $950{ }^{\circ} \mathrm{C}$ it is identical and at $1000{ }^{\circ} \mathrm{C}$ garnet has a higher $\mathrm{Mg} \#$ than melt. This is in excellent agreement with previous experiments by Green (1977) and Ellis (1986) who suggested that melts have a higher $\mathrm{Mg} \#$ than garnet below $1000{ }^{\circ} \mathrm{C}$ at $30 \mathrm{kbar}$ and below $900{ }^{\circ} \mathrm{C}$ at crustal 

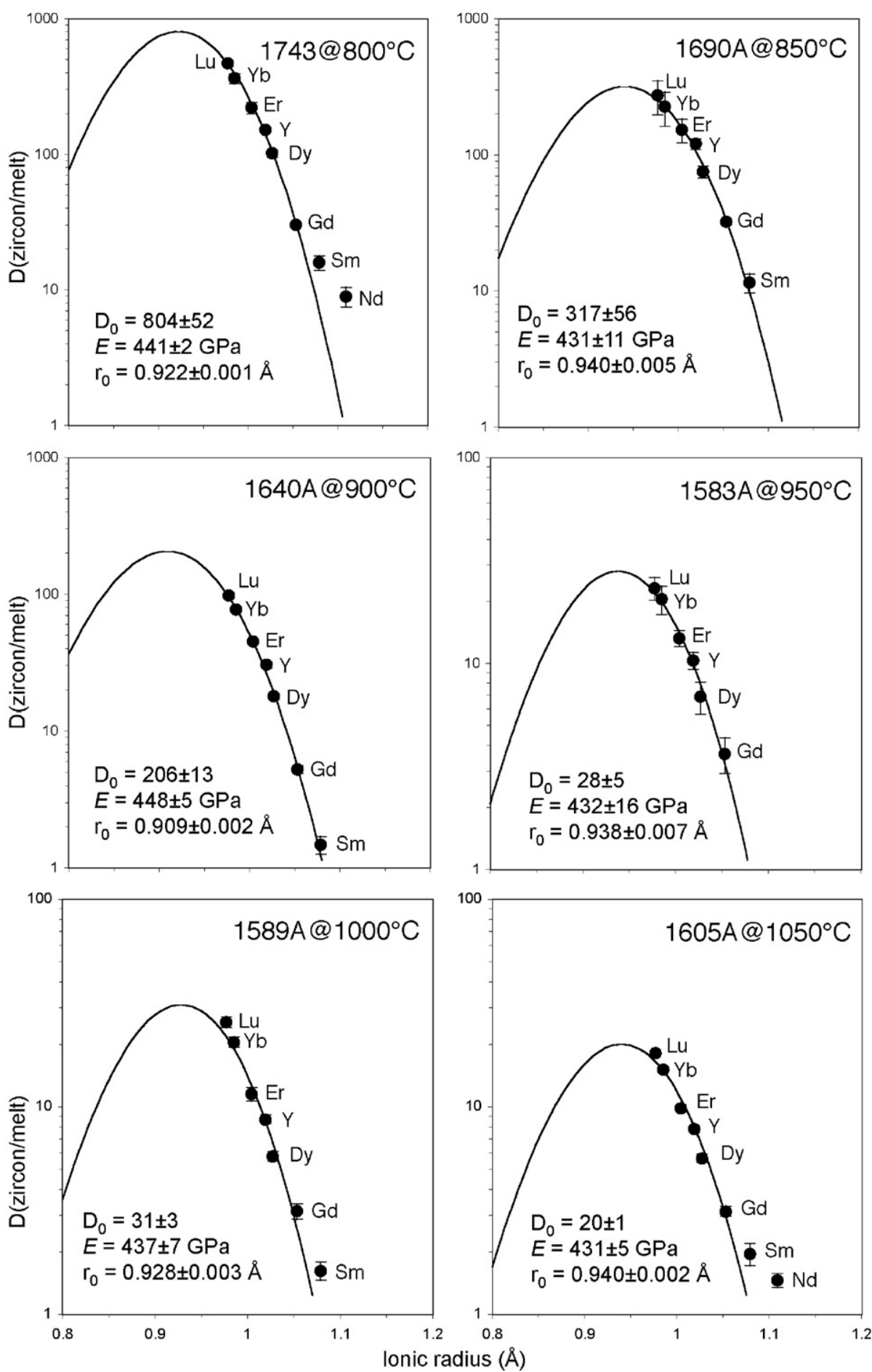

Fig. 8. Onuma diagrams for $D^{\mathrm{Zrn} / \mathrm{Melt}}$ for trivalent ions obtained at different temperatures. Data are fitted to the model constrained by Hanchar and Van Westrenen (personal comm., see Section 5.2. for details). Eight co-ordinated ionic radii from Shannon (1976). Data from Table 5.

pressures. This systematic change indicates that garnet formed at the final run temperature and not during the cooling step. Therefore textures and composition provide evidence for equilibrium between garnet and melt.
Melt displays a systematic change in $\mathrm{Zr}$ contents, which is buffered by zircon, with increasing temperature (see Section 6.4.). This provides evidence that the melt equilibrated at the desired run temperature. 
It is more difficult to assess equilibrium for zircon. Most of the zircon grains are elongated and display an idiomorphic shape. It was not possible to analyse different spots on single grains because they are far too small. Even microprobe analyses of trace element rich zircon resulted in mixed zircon-melt analyses. Nevertheless there is evidence that zircon approached chemical equilibrium within an experiment. Where possible, we analysed not only zircon-melt mixes but also staurolite-zircon mixes and regressed both for zircon composition. The zircon composition obtained with this method was identical within error suggesting that zircon equilibrated with the other experimental phases. Also the observation that we are able to fit the obtained zircon/melt partitioning to Onuma diagrams (Fig. 8) indicates that zircon and melt equilibrated. In fact, the applied analytical technique permitted recognition of clear disequilibrium between zircon and melt at temperatures below $900{ }^{\circ} \mathrm{C}$ where we had the initial heating step to $1050{ }^{\circ} \mathrm{C}$. In these experiments there is almost no fractionation in $D_{\mathrm{HREE}}^{\mathrm{Zrn} / \mathrm{Melt}}$ and at $750{ }^{\circ} \mathrm{C} D_{\mathrm{Gd}}^{\mathrm{Zrn}} /$ Melt is about a factor 5 higher than $D_{\mathrm{Yb}}^{\mathrm{Zrn} / \mathrm{Melt}}$, inconsistent with all published partitioning data. For this reason, we repeated these experiments without the heating step and obtained zircon/melt partitioning that can be fitted to Onuma diagrams (Fig. 8). The strongest argument that the zircon equilibrated with melt stems from the whole temperature series. The determined $D_{\mathrm{HREE}}^{\mathrm{Zrn} / \text { Melt }}$ displays a linear relationship in an Arrhenius plot (Fig. 7b). Such a systematic behaviour indicates that the bulk of zircon analysed in our mixed zircon-melt analyses equilibrated with the melt.

The starting material was doped with only a moderate amount of REE at a $400 \mathrm{ppm}$ level (Table 1) with the aim that the resulting partitioning is within the range of Henry's law. However, experiments at lower temperatures (especially 800 and $850{ }^{\circ} \mathrm{C}$ ) produced trace element-rich garnet ( $\mathrm{Lu}$ up to $5000 \mathrm{ppm}$ ) and zircon ( $\mathrm{Lu}$ up to $9000 \mathrm{ppm}$ ), for which it is possible that
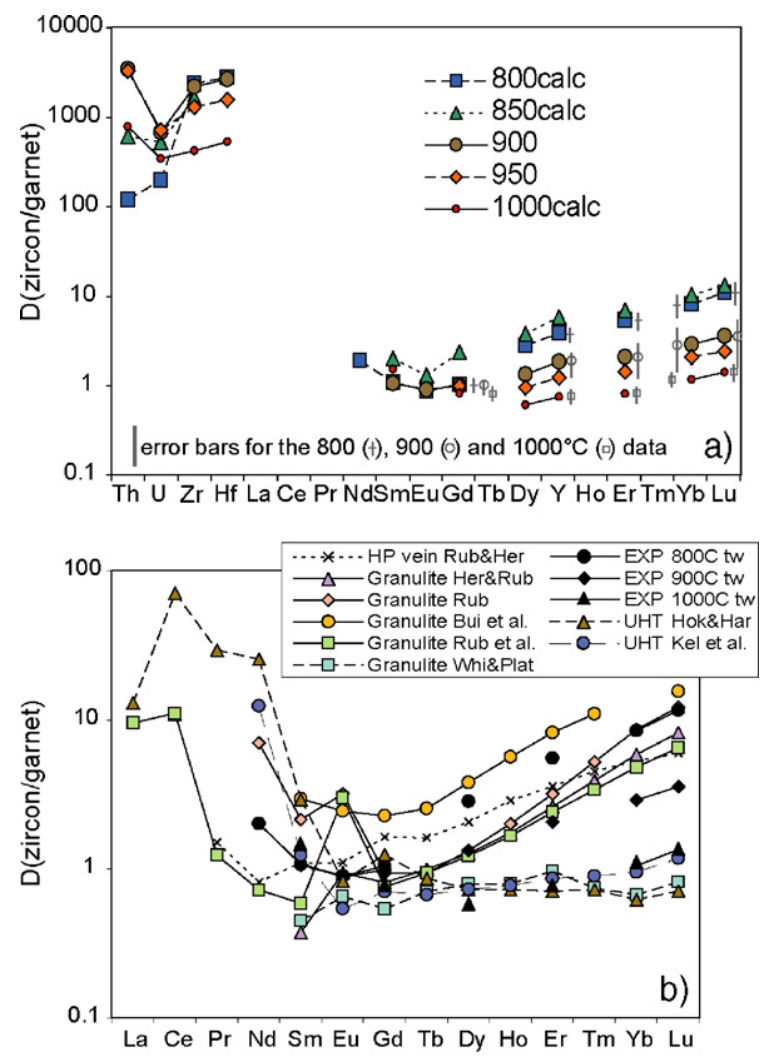

Fig. 9. Trace element distribution coefficients between zircon and garnet. a) Own data for different temperatures. 1 sigma errors for Gd, Y, Er, Yb and $\mathrm{Lu}$ are reported in grey beside the symbols. b) Own experimental data compared to literature data for different rock types. Sources: tw $=$ this work; Rub\&Her = Monviso HP vein of Rubatto and Hermann (2003); Her\&Rub = Malenco granulite of Hermann and Rubatto (2003); Rub = Reynolds granulite of Rubatto (2002); Bui et al. = Limpopo granulite of Buick et al. (2006); Rub et al. = Stafford granulite of Rubatto et al. (2006); Whi\&Plat = Betic granulite of Whitehouse and Platt (2003); Hok\&Har = UHT rock of Hokada and Harley (2004); Kel et al. = UHT rock of Kelly and Harley (2005). See Sections 5.3. and 6.5 for discussion. 
concentrations are too high to obey Henry's law. In a recent study, Prowatke and Klemme (2006) investigated the effect of trace element concentration in the starting material on titanite-melt partitioning at $1150{ }^{\circ} \mathrm{C}$. These authors found that Henry's law was satisfied for up to 5000-8000 ppm Sm in titanite. Additionally, Prowatke and Klemme (2006) stated that multiple REE, as in our experiments, might lead to deviation from Henry's law at lower concentrations. Their experiments showed that in such cases, the measured partitioning is lower than the partitioning in the region where Henry's law is obeyed but it is not expected to deviate more than a factor of two. The qualitative application of these results to our study would suggest that the garnet/melt and zircon/melt partitioning at low $T$ might be underestimated. If this is the case, the temperature dependence of garnet/melt and zircon/melt partitioning would be even more pronounced than what is documented here.

\subsection{Effect of temperature, pressure and composition on partitioning}

The presented data provides evidence for a strong temperature dependence of garnet/melt and zircon/melt trace element partitioning. $D_{\mathrm{Yb}}^{\mathrm{Zrn} / \mathrm{Melt}}$ increases over more than an order of magnitude from $\sim 20$ at $1000{ }^{\circ} \mathrm{C}$ to 350 at $800{ }^{\circ} \mathrm{C}$. As discussed above, the change in garnet/melt partitioning appears to be primarily a function of $T$, and secondarily of garnet composition. The increase of $D_{\mathrm{Yb}}^{\mathrm{Grt} \text { Melt }}$ from $\sim 10$ (at $950{ }^{\circ} \mathrm{C}$ ) to $\sim 40$ (at $800^{\circ} \mathrm{C}$ ) is less pronounced than what is seen in zircon.

The effect of pressure on partitioning has not been determined in this study. Adam and Green (2003) have reported a pressure series from 5 to $20 \mathrm{kbar}$ for REE partitioning between amphibole, clinopyroxene and mafic melt. Their data show that $D_{\mathrm{REE}}^{\mathrm{Am} / \mathrm{Melt}}$ and $D_{\mathrm{REE}}^{\mathrm{Cpx} / \text { Melt }}$ increase about a factor of 2 and 2.5 , respectively, with decreasing pressure from 20 to $5 \mathrm{kbar}$. It is therefore expected that also $D_{\mathrm{REE}}^{\mathrm{Zrn} / \text { elt }}$ will increase with decreasing pressure, but this effect is likely to be of less importance than the observed change with temperature. It is also expected that $D_{\mathrm{REE}}^{\mathrm{Zrn} / \mathrm{Melt}}$ and $D_{\mathrm{REE}}^{\mathrm{Grt} \text { Melt }}$ will change in a sympathetic way resulting in a less pronounced pressure sensitivity of $D_{\mathrm{REE}}^{\mathrm{Zm} / \mathrm{Grt}}$.

Melt composition will also affect partitioning to a certain extent (e.g. Taylor, 1988; Blundy and Wood, 2003) and consequently the experimental data set can be compared to intermediate to felsic rocks, whereas application to mafic rocks should be made with care. One factor that remains unknown is how much different water and phosphorus contents of the melt will affect the zircon/melt partitioning for REE. Higher phosphorus contents up to saturation with a phosphate might lead to an increase in $D_{\mathrm{REE}}^{\mathrm{Zn} / \mathrm{Melt}}$ and hence would lead to an increase of $D_{\mathrm{REE}}^{\mathrm{Zrn} / \mathrm{Grt}}$. Clearly more experimental studies are needed to properly assess the combined effect of temperature, pressure and melt composition on zircon/melt and zircon/garnet trace element partitioning.

\subsection{Zircon/melt partitioning}

On the basis of zircon separates and interstitial glass in alkaline volcanic rocks, Hinton and Upton (1991) predicted $D^{\mathrm{Zrn} / \text { Melt }}$ according to a linear fit that assumes a power law dependence of partition coefficients with ionic radius. Their calculated values are similar to our experimental results (Fig. 7d). They also predicted an increase in $D^{\mathrm{Zrn} / \text { Melt }}$ from MREE to HREE of more than two orders of magnitude, but our data indicate a smaller increase at any of the temperature investigated. Other studies determined $D^{\mathrm{Zrn} / \mathrm{Melt}}$ by analysing zircon separates and whole rock or glass compositions (e.g. Mahood and Hildreth, 1983; Murali et al., 1983; Fujimaki, 1986; Bea et al., 1994) (Fig. 7d), a technique that is often hampered by contamination, particularly for the LREE. A recent ion microprobe study of Thomas et al. (2002) measured partitioning between silica-rich (quartz diorite) melt inclusions and zircon. Good agreement is also seen with the data from Bea et al. (1994) and Sano et al. (2002), who used micro-beam techniques to measure zircon crystals from a rock (leucosome and dacite, respectively), which was taken as melt composition. In Bea et al. (1994) the estimate is too high for the LREE, likely because of melt contamination in the zircon measurement.

The majority of empirical $D_{\mathrm{HREE}}^{\mathrm{Zrn} / \mathrm{Melt}}$ data are close to the experimental results at $800{ }^{\circ} \mathrm{C}$ (Fig. 7d). The similarity of empirical data with the $800{ }^{\circ} \mathrm{C}$ experiment is reasonable considering the setting in which the empirical partitioning has been established. Partial melting in granulite-facies rocks (Bea et al., 1994) as well as zircon crystallization from felsic magmas (Sano et al., 2002) is likely to occur at temperatures of $\sim 800{ }^{\circ} \mathrm{C}$. The results of Thomas et al. (2002) are comparable to our $900{ }^{\circ} \mathrm{C}$ experiment. In fact, based on homogenisation temperature of the melt inclusions, Thomas et al. (2002) suggested that zircon and melt equilibrated between $920-960{ }^{\circ} \mathrm{C}$, in good agreement with our experiments. The good agreement between our experiments at high $P$ and empirical partitioning at low $P$ supports the hypothesis that pressure has a more limited effect on zircon/melt partitioning than temperature.

The large observed variation of zircon/melt partitioning provides further evidence that recalculation of melt compositions from zircon is quite difficult (e.g. Whitehouse and Kamber, 2002; Hoskin and Schaltegger, 2003 
and references therein). Hoskin and Schaltegger (2003) suggested that only in cases when zircon is an early crystallizing phase can reasonable melt composition be recalculated assuming equilibrium crystallization of zircon. Our new data shows that the temperature of zircon formation needs to be known in order to recalculate realistic REE melt compositions from which zircon crystallized.

\subsection{Zr solubility in melts}

Harrison and Watson (1983) and Watson and Harrison (1983) produced experimental data on $\mathrm{Zr}$ content of melt containing zircon, indicating that the $\mathrm{Zr}$ saturation changes with temperature and chemistry of the melt. This has become a widely used thermometer for granitic magmas containing zircon (see a review in Hanchar and Watson, 2003). The model of Watson and Harrison (1983) was based mainly on experiments performed between 860 and $1500{ }^{\circ} \mathrm{C}$ at pressure of $6 \mathrm{kbar}$. They concluded that pressure was likely to have little influence on the model because one experiment at $1.2 \mathrm{kbar}$ produced similar data. A comparison between our measured $\mathrm{Zr}$ content in the melt and the values obtained according to the model of Watson and Harrison (1983) for the same melt composition is plotted in Fig. 10 as a function of temperature. Both data sets define a linear trend that, in the case of our data, is displaced to lower $\mathrm{Zr}$ content. The $\mathrm{Zr}$ content of the melt that we measured is between 40 to $70 \%$ lower than what predicted by the model (Watson and Harrison, 1983).

In addition to confirming the trend documented by Watson and Harrison (1983), our data suggest that pressure might have a slight negative effect on $\mathrm{Zr}$ solubility in granitic melts. This finding is in agreement with trends observed in apatite and rutile saturated felsic melts, which show a decrease in the $\mathrm{P}$ and Ti contents with increasing pressure (Green and Adam, 2002). This observed decrease of $\mathrm{Zr}$ solubility in high pressure, hydrous granitic melts might be relevant when subduction-related melts are investigated.

\subsection{P-T-time paths using zircon and garnet}

Rubatto (2002) proposed that trace elements could be used to establish equilibrium and thus coexistence between specific garnet and zircon zones. This hypothesis has been since tested in natural rocks equilibrated at eclogite facies (Rubatto, 2002; Rubatto and Hermann, 2003; Whitehouse and Platt, 2003; Gilotti et al., 2004) granulite facies (Hermann and Rubatto, 2003; Buick et al., 2006; Rubatto et al., 2006) and UHT conditions (Hokada and Harley, 2004; Kelly and Harley, 2005). This new method allows relating ages to $P-T$ estimates in a more rigorous way, and can greatly improve the reliability of $P-T$-time paths and the calculation of metamorphic rates. However, studies on natural rocks may be subject to large uncertainties in partitioning because of mineral zoning (Rubatto, 2002; Whitehouse and Platt, 2003), which could partly explain the difference in distribution coefficients measured in natural samples (Fig. 9b). Our experimental data on zircon/garnet partitioning sets reference values for natural systems and has the potential to resolve some of the observed complexity. The experimentally determined $D^{\mathrm{Zrn} / \mathrm{Grt}}$ are always above unity for the HREE. The highest variation in $D^{\mathrm{Zrn} / \mathrm{Grt}}$ is encountered for MREE and LREE. This is probably related to problems to accurately determine these elements in natural samples, which are characterised by overall low concentrations and by complications arising from LREErich inclusions. There is good agreement between the experimental data at $800^{\circ} \mathrm{C}$ and granulite-facies samples, which equilibrated at similar temperatures (Rubatto, 2002; Hermann and Rubatto, 2003; Buick et al., 2006; Rubatto et al., 2006). In fact, most of the empirical data from granulites plot between the 800 and $900{ }^{\circ} \mathrm{C}$ experimental values (Fig. 9b). The partitioning reported for the Antarctica UHT rocks that recorded $1100{ }^{\circ} \mathrm{C}$ (Hokada and Harley, 2004; Kelly and Harley, 2005) are significantly lower but fit the experimental temperature trend by which $D^{\mathrm{Zrn} / \mathrm{Grt}}$ for the HREE decrease with increasing $T$. The experimental data suggests that the apparent discrepancy between different $D^{\mathrm{Zrn} / \mathrm{Grt}}$ obtained from natural samples could therefore be mainly due to

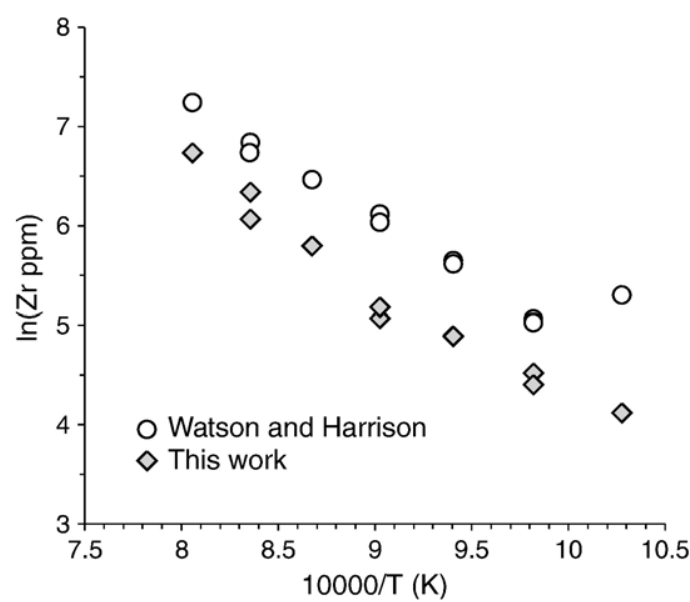

Fig. 10. Zr saturation in melt measured in this work (errors are smaller than symbols) compared with values calculated according to Watson and Harrison (1983) for the melt compositions of our experiments. 
variation in equilibration temperature of the rocks investigated. However, the $D^{\mathrm{Zrn} / \mathrm{Grt}}$ of Whitehouse and Platt (2003) obtained from a $750-800{ }^{\circ} \mathrm{C}$ granulite is close to unity and cannot be explained with the present data. This indicates that additional factors such as mineral composition, buffer paragenesis, melt composition or even the lack of sufficient melt to act as a flux might influence zircon/garnet trace element partitioning.

The conclusions reached in this study further strengthen the use of trace element partitioning between garnet and zircon to relate ages to metamorphic conditions. As shown in previous studies (Rubatto and Hermann, 2003; Kelly and Harley, 2005), inherited zircon that formed in protoliths free of garnet can be easily recognized on the basis of an inconsistent trace element partitioning with the rockforming garnet. Similarly, relic garnet formed during a previous metamorphic cycle can be recognized because of disequilibrium partitioning with metamorphic zircon equilibrated with the present rock assemblage (e.g. Rubatto, 2002). In these disequilibrium cases the composition of the two phases is so different that the pattern of the $D^{\mathrm{Zrn} / \mathrm{Grt}}$ can be opposite to the expected trend and/or the apparent values are one to two orders of magnitude different from what is expected.

More challenging is the recognition of (dis)equilibrium of zircon and garnet that formed during the same metamorphic cycle but at different stages, as attempted in a number of studies (Hermann and Rubatto, 2003; Hokada and Harley, 2004; Kelly and Harley, 2005; Buick et al., 2006; Rubatto et al., 2006). Even though this is in principle possible, the viability of this method was partly limited by the absence of experimental partitioning data. The new data set will assist in relating zircon formation to garnet growth especially in samples that display large variation in garnet trace element compositions. While our data set provides evidence that temperature plays a fundamental role, further studies are needed to quantify the influence of phase and melt composition, the buffer paragenesis and pressure on zircon/melt and zircon/garnet partitioning.

\section{Conclusions}

We determined trace element zircon-melt partitioning in experimental charges where the grain size of zircon is very small (a few $\mu \mathrm{m}$ ) by analysing a large number of mineral-melt mixtures by Laser Ablation ICP-MS and regressing the data to the composition of the mineral. We have shown with several tests that this method delivers reliable results with 1 sigma errors between 3 and $20 \%$.

We performed experiments at $20 \mathrm{kbar}$ and 800,850 , $900,950,1000$ and $1050{ }^{\circ} \mathrm{C}$ and demonstrated that there is an increase in zircon/melt trace element partitioning with decreasing temperature.

Our data confirm that $\mathrm{Zr}$ solubility in hydrous granitic melts is a function of temperature and thus can be used as a thermometer. However, our experiments, which were performed at $20 \mathrm{kbar}$, suggest that pressure has a small negative effect on $\mathrm{Zr}$ solubility in crustal melts. This effect is particularly relevant when subduction-related melts are investigated, where the temperature of the melt could be underestimated.

Large garnets coexisting with hydrous granitic melts were produced by heating the experiments to $1050{ }^{\circ} \mathrm{C}$ and then cooling to the desired temperature between 800 and $1000{ }^{\circ} \mathrm{C}$. Run products provide evidence for a significant temperature dependence of garnet/melt partitioning for REE. The $D_{\mathrm{HREE}}^{\mathrm{Grt} / \mathrm{Melt}}$ increases from about $10 \pm 2$ at $950{ }^{\circ} \mathrm{C}$ to about $40 \pm 7$ at $800{ }^{\circ} \mathrm{C}$. The presented experimental data at these relatively low temperatures is therefore useful to characterise partial melting processes in crustal rocks.

Trace element partitioning between zircon and garnet was obtained by either analysing the two phases equilibrated with a hydrous granitic melt in the same experiments or by combining zircon/melt and garnet/melt partitioning obtained in separate experiments. The combination of these two approaches permitted for the first time to experimentally establish equilibrium REE partitioning between garnet and zircon at $20 \mathrm{kbar}$ and in the given bulk composition. Both methods show that zircon contains more HREE than garnet, whereas the partitioning of MREE is close to unity. Our new data indicate that, at these conditions, the HREE partitioning between zircon and garnet decreases with increasing temperature. It is expected that pressure has a much less pronounced effect on zircon/garnet partitioning. The observed change in partitioning with temperature might thus provide the missing link between apparently contrasting sets of empirical zircon/garnet REE partitioning data. The experimental partitioning data form a basis to correlate zircon ages to garnet growth and hence to construct detailed pressure-temperature-time paths in high-grade metamorphic rocks.

\section{Acknowledgments}

The Electron Microscopy, Australian National University, is thanked for the access to SEM facilities. We are grateful to Dean Scott, Charlotte Allen and Nick Ware for their technical assistance. This work benefited from discussion with a number of colleagues: Willem Van Westrenen introduced us to the 
lattice strain model, John Hanchar and Willem Van Westrenen shared with us their zircon/melt model, Stephan Klemme helped with the technicalities of Onuma diagrams and offered useful comments. We are also grateful to David H. Green and Trevor H. Green for their inputs in the experimental set-up. Comments from Ross Taylor, Ian Buick, Eric Essene, James Brenan and Jon Blundy assisted in developing the present manuscript. The journal review of Martin Whitehouse, Andreas Möller and an anonymous reviewer are acknowledged. DR contribution was supported by the Australian Research Council and JH contribution by the Swiss National Science Foundation and the Australian Research Council.

\section{Appendix A. Supplementary data}

Supplementary data associated with this article can be found, in the online version, at doi:10.1016/j. chemgeo.2007.01.027.

\section{References}

Adam, J., Green, T.H., 2003. The influence of pressure, mineral composition and water on trace element partitioning between clinopyroxene, amphibole and basanitic melts. European Journal of Mineralogy 15, 831-841.

Bea, F., Pereira, M.D., Stroh, A., 1994. Mineral/leucosome traceelement partitioning in a peraluminous migmatite (a laser ablationICP-MS study). Chemical Geology 117, 291-312.

Blundy, J.D., Wood, B.J., 1994. Prediction of crystal-melt coefficients from elastic moduli. Nature 372, 452-454.

Blundy, J., Wood, B., 2003. Partitioning of trace elements between crystals and melts. Earth and Planetary Science Letters 210, 383-397.

Brice, J.C., 1975. Some thermodynamic aspects of the growth of strained crystals. Journal of Crystal Growth 28, 249-253.

Buick, I.S., Hermann, J., Williams, I.S., Gibson, R.L., Rubatto, D., 2006. Age and petrogenesis of garnet-cordierite-orthoamphibole gneisses from the Central Zone of the Limpopo Belt, South Africa. Lithos 88, 150-172.

Devine, J., Gardner, J., Brack, H., Layne, G., MJ, R., 1995. Comparison of microanalytical methods for estimating $\mathrm{H}_{2} \mathrm{O}$ contents of silicic volcanic glasses. American Mineralogist 80, 319-328.

Eggins, S.M., Rudnick, R.L., McDonough, W.F., 1998. The composition of peridotites and their minerals: a laser ablation ICP-MS study. Earth and Planetary Science Letters 154, 53-71.

Ellis, D.J., 1986. Garnet-liquid Fe2+-Mg equilibria and implications for the beginning of melting in the crust and subduction zones. American Journal of Science 286, 765-791.

Fujimaki, H., 1986. Partition coefficients of Hf, Zr, and REE between zircon, apatite and liquid. Contributions to Mineralogy and Petrology 94, 42-45.

Gilotti, J.A., Nutman, A.P., Brueckner, H.K., 2004. Devonian to Carboniferous collision in the Greenland Caledonides: $\mathrm{U}-\mathrm{Pb}$ zircon and $\mathrm{Sm}-\mathrm{Nd}$ ages of high-pressure and ultrahigh-pressure metamorphism. Contributions to Mineralogy and Petrology 148, 216-235.

Green, T.H., 1977. Garnet in silicic liquids and its possible use as a $\mathrm{P}-\mathrm{T}$ indicator. Contributions to Mineralogy and Petrology 65, $59-67$.

Green, T.H., Adam, J., 2002. Pressure effect on Ti- or P-rich accessory mineral saturation in evolved granitic melts with differing $\mathrm{K}_{2} \mathrm{O}$ / $\mathrm{Na}_{2} \mathrm{O}$ ratios. Lithos 61, 271-282.

Green, T.H., Blundy, J.D., Adam, J., Yaxley, G.M., 2000. SIMS determination of trace element partition coefficients between garnet, clinopyroxene and hydrous basaltic liquids at 2-7.5 GPa and $1080-1200{ }^{\circ} \mathrm{C}$. Lithos 53, 165-187.

Hanchar, J.M., Watson, B.E., 2003. Zircon saturation thermometry. In: Hanchar, J.M., Hoskin, P.W.O. (Eds.), Zircon. Reviews in Mineralogy and Geochemistry. Mineralogical Society of America, Washington, pp. 89-112.

Hanchar, J.M., et al., 2001. Rare earth elements in synthetic zircon: Part 1. Synthesis, and rare earth and phosphorous doping. American Mineralogist 86, 667-680.

Harrison, T.M., Watson, B.E., 1983. Kinetics of zircon dissolution and zirconium diffusion in granitic melts of variable water content. Contributions to Mineralogy and Petrology 84, 66-72.

Heaman, L.M., Bowins, R., Crocket, J., 1990. The chemical composition of igneous zircon suites: implications for geochemical tracer studies. Geochimica et Cosmochimica Acta 54, 1597-1607.

Hermann, J., 2002. Allanite: thorium and light rare earth element carrier in subducted crust. Chemical Geology 192, 289-306.

Hermann, J., Rubatto, D., 2003. Relating zircon and monazite domains to garnet growth zones: age and duration of granulite facies metamorphism in the Val Malenco lower crust. Journal of Metamorphic Geology 21, 833-852.

Hickmott, D.D., Shimizu, N., Selverstone, J., 1987. Trace-element zoning in a metamorphic garnet. Geology 15, 573-576.

Hinton, R.W., Upton, B.G.J., 1991. The chemistry of zircon: variations within and between large crystals from syenite and alkali basalt xenoliths. Geochimica et Cosmochimica Acta 55, 3287-3302.

Hinton, R.W., Macdonald, R., McGarvie, D.W., Tindle, A., Harley, S.L., 2003. The possible role of hydrogen in the substitution of rare earth elements into zircon. EGS-AGU-EUG General Assembly, Nice, France.

Hokada, T., Harley, S.L., 2004. Zircon growth in UHT leucosome: constraints from zircon-garnet rare earth elements (REE) relations in Napier Complex, East Antarctica. Journal of Mineralogical and Petrological Sciences 99, 180-190 (Special Issue).

Hoskin, P.W.O., 2000. Pattern of chaos: fractal statistics and the oscillatory chemistry of zircon. Geochimica et Cosmochimica Acta 64, 1905-1923.

Hoskin, P.W.O., Schaltegger, U., 2003. The composition of zircon and igneous and metamorphic petrogenesis. In: Hanchar, J.M., Hoskin, P.W.O. (Eds.), Zircon. Reviews in Mineralogy and Geochemistry. Mineralogical Society of America, Washington, pp. 27-62.

Hoskin, P.W.O., Kinny, P.D., Wyborn, D., Chappell, B.W., 2000. Identifying accessory mineral saturation during differentiation in granitoids magmas: an integrated approach. Journal of Petrology $41,1365-1396$

Kelly, N., Harley, S., 2005. An integrated microtextural and chemical approach to zircon geochronology: refining the Archean history of the Napier Complex, east Antarctica. Contributions to Mineralogy and Petrology 149, 57-84.

Linnen, R.L., Keppler, H., 2002. Melt composition control of $\mathrm{Zr} / \mathrm{Hf}$ fractionation in magmatic processes. Geochimica et Cosmochimica Acta 66, 3293-3301. 
Mahood, G., Hildreth, W., 1983. Large partition coefficients for trace elements in high-silica rhyolites. Geochimica et Cosmochimica Acta 47, 11-30.

Murali, A.V., Parthasarathy, R., Mahadevan, T.M., Sankar Das, M., 1983. Trace element characteristics, REE patterns and partition coefficients of zircons from different geological environments - a case study on Indian zircons. Geochimica et Cosmochimica Acta 47, 2047-2052.

Nicholls, I.A., Harris, K.L., 1980. Experimental rare earth element partitioning coefficients for garnet, clinopyroxene and amphibole coexisting with andesitic and basaltic liquids. Geochimica et Cosmochimica Acta 44, 287-308.

Onuma, N., Higuchi, H., Wakita, H., Nagasawa, H., 1968. Trace element partition between two pyroxenes and the host lava. Earth and Planetary Science Letters 5, 47-51.

Otamendi, J.E., Patiño Douce, A.E., 2001. Partial melting of aluminous metagreywackes in the northern Sierra de Comechingones, central Argentina. Journal of Petrology 42, 1751-1772.

Otamendi, J.E., de la Rosa, J., Patiño Douce, A.E., Castro, A., 2002. Rayleigh fractionation of heavy rare earths and yttrium during metamorphic garnet growth. Geology 30, 159-162.

Pearce, N.J.G., et al., 1997. A compilation of new and published major and trace element data for NIST SRM 610 and NIST SRM 612 glass reference materials. Geostandards Newsletter-the Journal of Geostandards and Geoanalysis 21, 115-144.

Prowatke, S., Klemme, S., 2006. Rare earth element partitioning between titanite and silicate melts: Henry's law revisited. Geochimica et Cosmochimica Acta 70, 4997-5012.

Rubatto, D., 2002. Zircon trace element geochemistry: distribution coefficients and the link between $\mathrm{U}-\mathrm{Pb}$ ages and metamorphism. Chemical Geology 184, 123-138.

Rubatto, D., Hermann, J., 2003. Zircon formation during fluid circulation in eclogites (Monviso, Western Alps): implications for $\mathrm{Zr}$ and $\mathrm{Hf}$ budget in subduction zones. Geochimica et Cosmochimica Acta 67, 2173-2187.

Rubatto, D., Hermann, J., Buick, I.S., 2006. Temperature and bulk composition control on the growth of monazite and zircon during low-pressure anatexis (Mount Stafford, central Australia). Journal of Petrology 47, 1973-1996.

Sano, Y., Terada, K., Fukuoka, T., 2002. High mass resolution ion microprobe analysis of rare earth elements in silicate glass, apatite an zircon: lack of matrix dependency. Chemical Geology 184, 217-230.

Shannon, R.D., 1976. revised effective ionic radii and systematic studies of interatomic distances in halides and chalcedonides. Acta Crystallographica A32, 751-767.
Sisson, T.W., Bacon, R., 1992. Garnet/high-silica rhyolite trace element partition coefficients measured by ion microprobe. Geochimica et Cosmochimica Acta 56, 2133-2136.

Spandler, C., Hermann, J., Rubatto, D., 2004. Exsolution of thortveitite, yttrialite and xenotime during low temperature recrystallization of zircon from New Caledonia, and their significance for trace element incorporation in zircon. American Mineralogist 89, 1795-1806.

Speer, J.A., 1982. Zircon. In: Ribbe, P. (Ed.), Orthosilicates. Reviews in Mineralogy. Mineralogical Society of America, Washington D.C., pp. $67-112$.

Taylor, S.R., 1988. The significance of the rare earths in geochemistry and cosmochemistry. In: Gschneidner, K.A.J., Eyring, L. (Eds.), Handbook of the Physics and Chemistry of Rare Earths. Elsevier Science Publishers B.V., Amsterdam, pp. 485-578.

Thomas, J.B., Bodnar, R.J., Shimizu, N., Sinha, A.K., 2002. Determination of zircon/melt trace element partition coefficients from SIMS analysis of melt inclusions in zircon. Geochimica et Cosmochimica Acta 66, 2887-2901.

Van Westrenen, W., Blundy, J., Wood, B., 1999. Crystal-chemical controls on trace element partitioning between garnet and anhydrous silicate melt. American Mineralogist 84, 838-847.

Van Westrenen, W., Allan, N.L., Blundy, J.D., Purton, J.A., Wood, B.J., 2000. Atomistic simulation of trace element incorporation into garnets-comparison with experimental garnet-melt partitioning data. Geochimica et Cosmochimica Acta 64, 1629-1639.

Van Westrenen, W., Wood, B.J., Blundy, J.D., 2001. A predictive thermodynamic model of garnet-melt trace element partitioning. Contributions to Mineralogy and Petrology 142, 219-234.

Watson, B.E., 1980. Some experimentally determined zircon/liquid partition coefficients for the rare earth elements. Geochimica et Cosmochimica Acta 44, 895-897.

Watson, B.E., Harrison, M.T., 1983. Zircon saturation revisited: temperature and composition effects in a variety of crustal magma types. Earth and Planetary Science Letters 64, 295-304.

Whitehouse, M.J., Kamber, B.S., 2002. On the overabundance of light earth elements in terrestrial zircons and its implication for Earth's earliest magmatic differentiation. Earth and Planetary Science Letters 204, 333-346.

Whitehouse, M.J., Platt, J.P., 2003. Dating high-grade metamorphism: constraints from rare-earth elements in zircon and garnet. Contributions to Mineralogy and Petrology 145, 61-74.

Wood, B.J., Blundy, J.D., 2002. The effect of $\mathrm{H}_{2} \mathrm{O}$ on crystal-melt partitioning of trace elements. Geochimica et Cosmochimica Acta $66,3647-3656$. 